\title{
Technological Applications of Natural Colorants in Food Systems: A Review
}

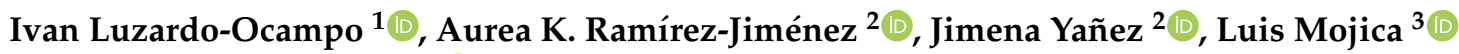 \\ and Diego A. Luna-Vital ${ }^{2, *(D)}$ \\ 1 Instituto de Neurobiología, Universidad Nacional Autónoma de México (UNAM), \\ Santiago de Querétaro, QRO 76230, Mexico; ivan.8907@gmail.com \\ 2 Tecnologico de Monterrey, School of Engineering and Science, Avenida Eugenio Garza Sada 2501 Sur, \\ Monterrey, N. L. 64849, Mexico; aramirezj@tec.mx (A.K.R.-J.); A00832586@itesm.mx (J.Y.) \\ 3 Tecnología Alimentaria, Centro de Investigación y Asistencia en Tecnología y Diseño del Estado de \\ Jalisco (CIATEJ), A. C., Camino Arenero \#1227 Col. El Bajío, Zapopan, JAL 45019, Mexico; lmojica@ciatej.mx \\ * Correspondence: dieluna@tec.mx
}

Citation: Luzardo-Ocampo, I.;

Ramírez-Jiménez, A.K.; Yañez, J.;

Mojica, L.; Luna-Vital, D.A.

Technological Applications of Natural Colorants in Food Systems: A Review. Foods 2021, 10, 634. https://doi.org/ 10.3390 /foods 10030634

Academic Editor:

Beatriz Gandul-Rojas

Received: 21 February 2021

Accepted: 12 March 2021

Published: 17 March 2021

Publisher's Note: MDPI stays neutral with regard to jurisdictional claims in published maps and institutional affiliations.

Copyright: (c) 2021 by the authors. Licensee MDPI, Basel, Switzerland. This article is an open access article distributed under the terms and conditions of the Creative Commons Attribution (CC BY) license (https:// creativecommons.org/licenses/by/ $4.0 /)$.

\begin{abstract}
Natural colorants have emerged as an alternative to their synthetic counterparts due to an existing health concern of these later. Moreover, natural-food colorants are a renewable option providing health benefits and interesting technological and sensory attributes to the food systems containing them. Several sources of natural colorants have been explored aiming to deliver the required wide color range demanded by consumers. This review aimed to compare and discuss the technological applications of the main natural-food colorants into food system in the last six years, giving additional information about their extraction process. Although natural colorants are promising choices to replace synthetic ones, optimization of processing conditions, research on new sources, and new formulations to ensure stability are required to equate their properties to their synthetic counterparts.
\end{abstract}

Keywords: anthocyanins; betalains; carotenoids; colorants; extraction technologies; food systems; novel sources; phycobiliproteins; pigments; technological properties

\section{Introduction}

Modification or preservation of the visible appearance of foods is perhaps one of the main applications of natural or artificial colorants [1]. Although the food ingredient industry is more devoted to develop synthetic colorants due to their stability, attractive color, and low cost, natural food-colorants are gradually being preferred due to the changing consumers' lifestyle and increased concerns about potential adverse health effects and environmental damage caused by synthetic colorants [2]. For instance, some synthetic colorants have been linked to allergic reactions in susceptible individuals and six of them (tartrazine E102, quinoline yellow WS E104, sunset yellow FCF E110, carmoisine E122, ponceau 4R E124, and Allura red AC E129) are associated to increased hyperactive behavior in children [3]. Moreover, the use of natural colorants can provide technological and bioactive functionalities to those foods in which they are applied, delivering additional value-added properties [4].

Nowadays, natural-food colorants have found their niche for valuable food applications. Single-phase coloring systems such as baking products (solid phase) or drinks (liquid phase) have been successfully assayed with natural colorants such as carotenoids or anthocyanins (ANC) [5]. In addition, as genetical modification have been explored to increase the concentration of natural colorants in plants, there is more interest in using these procedures to increase the plants' production yield of colorants and find more suitable applications to be used in food applications, together with technological treatments aiming to stabilize these colorants [6]. 
Different natural colorants have been commercially exploited and approved for their use in the USA and the European union such as ANC (grape skin extract, grape color extract, berry fruit juice, or carrot and cabbage juices), carotenoids (annatto from Bixa orellana L., astaxanthin from Paracoccus carotinifaciens or Phaffia rhodozyma; b-carotene from carrots, carrot oil, corn endosperm, and bell pepper from Capsicum annuum L.), chlorophyls from alfalfa (Medicago sativa), curcuminoids from turmeric (Curcuma longa L.), betalains from beet (Beta vulgaris L.) powder, carminic acid from cochineal (Dactylopius coccus) extract, and caramel from heating of sugars [7]. Beyond these sources, novel plants and plantbased materials and fruits, microorganisms, and insects have been considered for such purpose [8]. Colorants can be added to food systems after a technological extraction or could be part of the colored raw material. However, as some of the natural bioactive compounds that chemically constitute these colorants can be lost due to the matrix storage and processing conditions, some of them can be encapsulated to take advantage of their technological and biological properties [9]. In addition, encapsulated colorants are easier to handle and often exhibit enhanced physicochemical properties such as better solubility, stability, and flow properties [10]. The preservation of their coloring properties can be achieved by adding biopolymers such as heat-denatured whey protein isolate to reduce ANC complexation with ascorbic acid [11]. Other mechanisms involve using glutathione, dihydrolipoic acid, cysteine, and cysteine-derivatives to anchor anthocyanidins; sugars and calcium carbonate as $\mathrm{pH}$-modifiers; aromatic acyl groups to acylate the $3^{\prime}$ position of the anthocyanin, or metal ions to form ANC-anthocyanidins complex suspended un polysaccharide matrices [12].

Food colorants play a crucial role in food production, masking unpleasant attributes or enhancing the food products' natural properties [1]. Therefore, based on their color, they can also be used for specific purposes. For instance, ANC are highly common watersoluble flavonoids exhibiting $\mathrm{pH}$-dependent colors from red to blue, and recognized by several bioactive properties such as antioxidant, anti-inflammatory, hypoglycemic, and chemopreventive effects [13]. Carotenoids are highly appreciated for their red, orange, and yellow color, primarily fruits and vegetables, contributing to desirable flavors in food and beverages [14]. Betalains are other type of colorants that have proven to be the most promissory candidates to replace Allura Red AC (Red 40), a synthetic colorant that contains benzidine, a potential human and animal carcinogen [15].

In this review, we compare and discuss some of the most recent findings in the last six years regarding the technological use of natural colorants in food systems, not only at a commercial, but also at an experimental level, providing a larger perspective on the functional aspects of colorants to be extensively used in the food industry, primarily aiming to increase the organoleptic value and enhance the natural color of food products. Furthermore, a brief description of the most important natural pigments used in the food industry and the industrial methods of production are also covered.

\section{Natural Pigments Used in the Food Industry}

Despite the wide range of natural pigments than have been used in the food industry, ANC, carotenoids, phycobiliproteins, betalains, and chlorophylls remain as the most commonly used for food applications. Some representative chemicals structures from these natural colorants are depicted in Figure 1. 


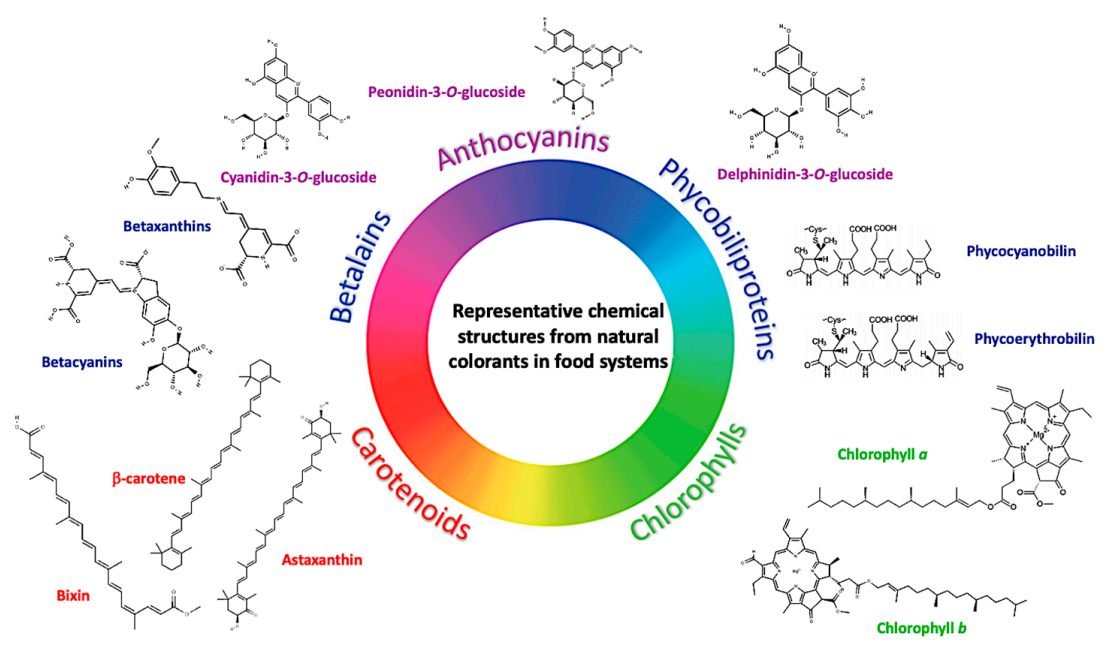

Figure 1. Representative chemical structures from the most common types of natural colorants applied in food systems. The chemical structures were downloaded from https:/ / pubchem.ncbi.nlm. nih.gov (accessed on 21 February 2021). Chemical structures from phycobiliproteins were adapted from Hsieh-Lo et al. [16] with permission of Elsevier or applicable copyright owner.

\subsection{Anthocyanins (ANC)}

Anthocyanins (from Greek anthos, meaning flower and kyáneos meaning dark blue), are water-soluble vacuolar polyphenolic pigments members of the flavonoid group. Their presence in different plant organs gives the leaves, flowers, and fruits colors from redorange to blue-purple [17]. Their basic structure is a flavan nucleus consisting of two aromatic rings: benzopyrylium and a phenolic ring joined by glucoside at carbon atom 3 of the benzopyrylium. ANC are considered the glycosylated forms of anthocyanidins since they are made up of an anthocyanidin molecule, the aglycone, to which sugar is bound through beta-glycosidic interactions such as glucose, galactose, rhamnose, and arabinose, commonly conjugated to the $\mathrm{C} 3$ hydroxyl group in the C-ring (Figure 1). The instability of anthocyanidins causes ANC to be found almost exclusively in their glycosylated form $[17,18]$. The presence of conjugated bonds in ANC results in red, blue, and purple colors, mainly depending on $\mathrm{pH}$ conditions [19].

What differentiates ANC from each other is the number of hydroxyl groups in the molecule, the degree of methylation of these hydroxyl groups, the nature and number of sugars bound to the molecule, their position of binding, and the nature and number of aliphatic or aromatic acids attached to the sugars [18]. The prevalent ANC forms in nature are six and represent $\sim 90 \%$ of all ANC identified to date: pelargonidin, cyanidin, peonidin, delphinidin, petunidin, and malvidin. All of them are synthesized in plants by the phenylpropanoid pathway $[17,20]$. ANC are a very popular natural food-colorants susceptible to several $\mathrm{pH}$-dependent color gradients, used in very popular foodstuff such as beverages, desserts, ice cream, and dairy products [12,21]. Some commercial ANC are grouped by E163 food additive, a purple colorant derived from grape skin, such as cyanidin (E163a), delphinidin (E163b), malvidin (E163c), pelargonidin (E163d), peonidin (E163e), petunidin (E163f), grape skin extract (E163ii), ANC mixture (E163ii), and blackcurrant extract (E163iii) [19,22]. Among the major health properties associated to ANC are its anti-cancer activity linked to chemopreventive and chemoprotective effects in vivo and in vitro in several cancer cell lines [23], antioxidant, and anti-inflammatory benefits [24,25].

\subsection{Carotenoids}

Based on their functional groups, carotenoids are classified in xanthophylls (oxygencontaining groups: $\beta$-cryptoxanthin, lutein, and zeaxanthin) and those having just carbon chains ( $\alpha$-carotene, $\beta$-carotene, and lycopene, among others) (Figure 1). Due to their hydrophobicity, they are mainly extracted using organic solvents, and depending on the 
natural source, the raw material might require a series of pretreatment stages [21]. Together with technological features (yellow, orange, and red color shades), most of them provide health benefits. For example, lycopene, a bioactive red colored pigment naturally found in red fruits, provides antioxidant properties with interesting health benefits linked to reduced cancer, cardiovascular disease, or diabetes risk [26]. Vitamin A is an essential carotenoid required for a plethora of metabolic purposes in the human body (immunity, growth development, and vision) [27]. Lutein and zeaxanthin provide ocular benefits and could improve the cognitive performance in elderly populations [28]. Alternative sources of carotenoids are microalgae, e.g., Dunaliella algae produce $\beta$-carotene under stress conditions, whereas Haematococcus pluvialis can produce astaxanthin [29]. Fucoxanthin is one of the most abundant carotenoids in nature, mainly extracted from brown macroalga such (class Phaeophyta: Undaria, Sargassum, Laminaria, Eisenia, Alaria, Cystoseira, and Hijikia), exhibiting interesting properties in those food products in which has been added, such as photoprotective, anti-obesity, anti-inflammatory, neuroprotective, anti-diabetic, antioxidant, and anti-cancer effects [30].

Some of the major technological applications of carotenoids include meat products (sausages), vegetable oils, and butter. Carotenoids are recognized as GRAS by several regulatory agencies such as the Food and Drug Administration (FDA) and the European Food Safety Authority (EFSA). However, acceptable daily intake (ADI) has been proposed for lutein $(1 \mathrm{mg} / \mathrm{kg}$ body weight, BW/day), lycopene $(0.5 \mathrm{mg} / \mathrm{kg} \mathrm{BW} /$ day $)$, zeaxanthin $(0.75 \mathrm{mg} / \mathrm{kg} \mathrm{BW} /$ day), $\beta$-carotene ( $<15 \mathrm{mg} / \mathrm{kg} \mathrm{BW} /$ day), bixin $(6 \mathrm{mg} / \mathrm{kg} \mathrm{BW} /$ day), and norbixin $(0.4 \mathrm{mg} / \mathrm{kg} \mathrm{BW} /$ day) [27]. Their use as colorant additives and functional ingredients is challenging due to their water insolubility, instability, and low bioavailability, and suitable alternatives have been developed, such as carotenoid delivery in water-dispersible products, colloidal suspensions, emulsions, and colloidal dispersions [31].

\subsection{Betalains}

Betalains are water-soluble pigments chemically based on nitrogenous-functional groups (Figure 1), classified into red violet betacyanins and yellow betaxanthins. The being betanin obtained from red beetroot (Beta vulgaris) was the first FDA-approved betalain [21] Betanins are used in confections, ice cream, yogurt, ready-made frostings, cake mixes, and beverages, among other applications [32]. However, betalains extracted from plants like cactus pear (Opuntia ficus-indica L. Mill. cv. "Gialla": proline-betaxanthin, $\gamma$-aminobutyric acid-betaxanthin, $\mathrm{C}_{15}$-stereoisomers betanin/isobetanin, and 2-decarboxy-betanin), Celosia argentea (miraxanthin- $\mathrm{V}$ or dopamine-betaxanthin, 3-methoxytyramine-betaxanthin, and (S)-tryptophan-betaxanthin), ulluco (Ullucus tuberosus Caldas: phyllocatin, gomphrenin III, betanin, and vulgaxanthin) [33], and Stenocereus sp. have been characterized [34].

Several technological efforts have been made to use betalains in food systems. However, these pigments are highly light- and high-temperature sensitive and might deliver an unappealing earthy taste to food products [8]. Nonetheless, betalains display higher water solubility, increased coloring potential, and better neutral $\mathrm{pH}$-stability compared to ANC [21].

\subsection{Other Pigments Potential Used in the Food Industry}

Chlorophylls are pigments widely distributed in green fruits and vegetables, structurally composed by a porphyrin ring chelated (intramolecular bond) with a magnesium atom. Chlorophyll also contains a fifth ring beyond the four pyrrole-like rings and a chain of propionic acid esterified with phytol $\left(\mathrm{C}_{20} \mathrm{H}_{39}\right)$ (Figure 1). The main chlorophylls found in plants are $a$ and $b$ in a 3:1 proportion in chloroplasts [35]. Chlorophylls exhibit several derivatives depending on high temperature, oxygen availability and changes in $\mathrm{pH}$ (pheophytins, chlorophyllides, phephorbides, piroderivatives, chlorin-type derivatives, and other allomerized compounds). Chlorophylls could exert biological activities such as antioxidants, antimutagenics, and anticancer activities [36]. In the food industry, chlorophylls are identified as E140i colorant and copper-chlorophylls as E141i colorant. The corresponding water-soluble forms, chlorophylins (E141ii) and copper-chlorophylins 
(E141ii) are also marketed. However, one of the most used chlorophyll sources is the Spirulina extract, which has approved use in the USA (spirulina from Arthrospira platensis) to be added to confections, frostings, ice cream, and frozen desserts, beverage mixtures and powders, yogurts, custards, puddings, among other food applications [37].

Phycobiliproteins are another source of blue-protein pigments, more stable compared to ANC at $\mathrm{pH}$ beyond the blue-range for these latter compounds ( $\mathrm{pH}$ : 5-7) [16] (Figure 1), although ANC are more stable at acidic $\mathrm{pH}$. This photosynthetic pigment is formed by fluorescent phycobiliproteins attached to the thylakoid membrane of the algae chloroplasts and chemically are built up of chromophores (bilins or open-chain tetrapyrroles) linked to thioether covalent bonds to an apoprotein [1]. Phycobiliproteins are classified into three categories: phycoerythrin (red color), phycocyanin (blue color), and allophycocyanin (bluish green color), and consist of a protein-pigment complex [38]. Phycobiliproteins can be extracted from Spirulina (A. platensis) phycobiliproteins, stable at $\mathrm{pH} 5.0-7.5\left(25^{\circ} \mathrm{C}\right)$ and predominantly used for color confections, gum, dairy products, and soft drinks. However, $\mathrm{pH}$-stable solutions are being explored to expand their use [21]. Moreover, phycobiliproteins are very thermolabile, losing their color intensity at $60{ }^{\circ} \mathrm{C}$ for $30 \mathrm{~min}$ in neutral solutions. Technological approaches such as high-pressure processing have been used to pasteurize beverages at low temperatures as an alternative for using these pigments [39].

\section{Industrial Methods of Production}

\subsection{Electric Field-Based Technologies}

Electric field (EF)-based technologies are emergent processes with the potential for the rapid and uniform thermal treatment of materials. Ohmic heating $(\mathrm{OH})$ and pulsed electric fields (PEF) are included in this category. Although it is not common to use these methods to extract natural colorants, some studies have addressed the potential of EF on the stability, functionality, and application of biomolecules. In addition, the electric field's non-thermal effects (mainly electroporation) seem to enhance the extraction of compounds $[40,41]$.

\subsection{Ohmic Heating}

With this method, an alternating electrical current is passed through a material. Consequently, the material is internally heated from the core to the outer material's surface due to the food's electrical resistance [42]. This feature is the main innovation of $\mathrm{OH}$, making it a highly energy-efficient process suitable for rapid and uniform plant material processing. Using this technology, plants are not over-processed, and minimal changes in phytochemicals and color are produced [43].

Previous studies have used $\mathrm{OH}$ to extract phenolic compounds, mainly ANC, from different plant tissues $[40,41,44-46]$. The best conditions to extract polyphenols from wheat bran using $\mathrm{OH}$ were set at $20 \mathrm{~V} / \mathrm{cm}, 80^{\circ} \mathrm{C}$, and $10 \mathrm{~min}$, using water instead of the solvents commonly used to extract phenolic compounds [1]. A recent study also evaluated the extraction yield of ANC from Solanum tuberosum L. var. Vitelotte, a colored potato with blue and violet tones, using $\mathrm{OH}$ at different temperatures and voltages [40]. An $85 \%$ recovery of total anthocyanidins (TA) was achieved at $90{ }^{\circ} \mathrm{C}$ and $15 \mathrm{~V}$ after 10 min holding time, compared with a conventional thermal treatment that yielded 73\% recovery. This effect depended on the time and temperature applied, but enhanced by the non-thermal effects that might cause the potato tissues' permeabilization due to an electroporation phenomenon [40,47]. The main pigments extracted from potatoes were petunidin glucosides, malvidin, and delphinidin, responsible for the purple color. Given the antioxidant nature of ANC, this extract may be a functional colorant in foods and beverages, although its stability has not yet been studied.

A colorant powder was obtained from black rice bran (Oryza sativa L.) with ohmic heating-assisted solvent extraction [45]. The colorant yield obtained (up to 20.63\%) was significantly higher compared to a steaming extraction process (17.64\%). Dark purple ANC (cyanidin-3-O-glucoside or C3G, delphinidin, cyanidin, and pelargonidin) were successfully extracted with $\mathrm{OH}$, and tocopherols such as $\gamma$-Oryzanol. Moreover, the solubility 
and color of the powder were not affected by the $\mathrm{OH}$ process; essential parameters used when evaluating the feasibility of a method for industrial applications. ANC extraction was enhanced by the electric field that causes cell wall permeabilization, allowing a higher and homogeneous release of intracellular components [41]. This effect was also observed for ANC ethanolic extraction from red grape pomace after $\mathrm{OH}$ application [41], with a $36 \%$ yield at $400 \mathrm{~V} / \mathrm{cm}$.

By-products such as peels and vine pruning residues (VPR) can also be used as sources of colorants. VRP is a good source of polyphenols. The $\mathrm{OH}$ technology has been used to obtain ethanol-water polyphenol extracts from this material $\left(840 \mathrm{~V} / \mathrm{cm}, 80^{\circ} \mathrm{C}\right.$ and $60 \mathrm{~min}$ extraction). Moreover, VP extracts may have beneficial effects on health such as antioxidant capacity, antimicrobial and anticancer activity against several cancer cell lines including HepG2, MDA-MB-231, MCF-7, and Caco-2 [48].

Color stability is an important feature when evaluating the feasibility and application of industrial systems. Processing conditions significantly affect this stability, as reported for ANC, carotenoids, and fungal pigments exposed to $\mathrm{OH}$. Typically, the $\mathrm{OH}$ methods reach a temperature higher than $70^{\circ} \mathrm{C}$, at which phenolic compounds degrade. As shown for blueberry (Vaccinium spp.) pulp treated by $\mathrm{OH}$, ANC degradation depends on the temperature-electric field combination [6]. At high voltages $(>200 \mathrm{~V})$, degradation was larger than the observed with conventional heating, and depended on the total solids content. In another study, a red extract produced by Penicillium purpurogenum GH2 incorporated in a beverage model system was processed with $\mathrm{OH}$ for microbial inactivation at $30 \mathrm{~V}$ and 0-80 min holding time [49]. The degradation kinetics showed lower stability for the samples treated with $\mathrm{OH}$ compared with conventional pasteurization. These observations indicate that the thermal effect and the concomitant influence of electric field and matrix compositions must be taken into account to maximize ANC yield and stability.

\subsection{Pulsed Electric Fields (PEF)}

This non-thermal technology uses high electric voltage in the $5-50 \mathrm{kV} / \mathrm{cm}$ range applied to food in short pulses $(<1 \mathrm{~s})$. Electroporation is the main accepted phenomenon occurring throughout the PEF process. Once the electric field is applied, it modifies the trans-membrane potential due to the accumulation of charges, which leads to membrane disruption and the release of intracellular components [50,51]. Since processing time is brief, degradation of bioactive compounds and natural colorants is expected to be minimal. However, several studies demonstrate that temperature, electric field strength, and time must be controlled to assure natural colorants' optimal extraction.

Several works have extracted colorants from diverse plant species. A method based on PEF extraction of ANC was optimized for Beibinghong (Vitis amurensis Rupr.) [52]. The optimal conditions were found with a response surface model: four pulses at $15.08 \mathrm{kV}$ to recover $166 \mathrm{mg}$ ANC. In another work, PEF pretreatment for aqueous and ethanolic extraction was tested for the recovery of ANC from purple-fleshed potato (Ipomoea batatas L.) [53]. Processing time was the variable with the greatest effect on ANC yield, whereas electric field strength and temperature improved cell permeability. PEF allowed the use water as a solvent and decreased the temperature and processing time to obtain a similar ANC yield than the untreated samples (higher temperature and using ethanol as solvent) due to the cell permeabilization effect caused by the PEF pretreatment.

Other colorants, including betalains, astaxanthin, chlorophyll, and $\beta$-phycoerythrin, have also been extracted with PEF [54-57]. Betalains were extracted from red beet (Beta vulgaris L.) using PEF-assisted aqueous extraction [54]. With PEF, the maximum recovery $(95 \%)$ and the minimal color degradation $(10 \%)$ were reached at low temperature $\left(30{ }^{\circ} \mathrm{C}\right)$, whereas the untreated samples needed higher temperature to reach $>80 \%$ yield. In other study, PEF were used to disrupt microalgal biomass (Haematococcus pluvialis) and extract astaxanthin (pink/red color carotenoid) [55]. Applying 10-80 pulses of $5 \mathrm{~ms}$ at $0.2-1 \mathrm{kV} / \mathrm{cm}$ for $6 \mathrm{~h}$, it was possible to observe a twofold increase in the colorant yield compared with the untreated sample. The solvent used had an important influence on the colorant 
recovery, methanol and ethanol were the best diluents in this experiment. In parallel work, the authors extracted $\beta$-phycoerythrin, a water-soluble red colorant present in the microalga Porphyridium cruentum [56]. This compound can be used in the food, cosmetic and pharmaceutical field. Interestingly, this study showed a strong correlation between the permeabilization percentage of cells treated by PEF and the extraction efficiency. Even at low intensities $(\sim 4 \mathrm{kV} / \mathrm{cm})$, high cell damage was observed and allowed nearly a $100 \%$ recovery of $\beta$-phycoerythrin when followed by a $24 \mathrm{~h}$ incubation in citrate-phosphate McIlvaine buffer. These studies show the importance of testing the specific conditions to maximize cell permeabilization before colorant extraction.

PEF have shown to be a suitable method to preserve chlorophyll stability extracted from spinach (Spinacia oleracea L.) [14]. Once the colorant was extracted with an ethanol solution, PEF were applied to the chlorophyll extract with the following conditions: 0-26 kV/cm, 20-45 ${ }^{\circ} \mathrm{C}$, and $0.32 \mathrm{~ms}$ as effective treatment time. The maximum chlorophyll recovery $(14.62 \mathrm{mg} / \mathrm{mL})$ was achieved at $35^{\circ} \mathrm{C}$ and the highest electric field strength $(26.7 \mathrm{kV} / \mathrm{cm})$. The structural characterization by Fourier Transform Infrared (FT-IR) and $X$-ray (XR) diffraction showed a relatively higher stability after the PEF treatment. According to the authors, PEF induced chemical changes in the pyrrole ring and favored the formation of chlorophyll aggregates that increase the stability of the colorant. As observed, PEF can be used not only as pretreatment, but also as a method to increase or at least, to lessen colorant degradation.

\subsection{High-Pressure-Assisted Extraction (HPE)}

High-pressure-assisted extraction (HPE) obeys the isostatic principle, which states the process is volume-independent, or that pressure is transmitted instantaneously and uniformly throughout a sample, with no pressure gradients [58]. This methodology is characterized by using low or room temperatures, and pressure ranges from 100 to $600 \mathrm{MPa}$ [59].

$\mathrm{HPE}$ is considered one of the most recent potential extraction techniques since heat is unnecessary, and therefore, the damaging effects on bioactive compounds are avoided, particularly to heat-labile compounds. As the pressure increases, there is a slight increase in temperature of $3{ }^{\circ} \mathrm{C}$ per $100 \mathrm{MPa}$, which is neglected because it is not enough to produce degradation by heat [60]. HPE has other advantages: faster extraction time from hours to minutes, lower solvent requirement, and the possibility of combining different solvents, higher extraction yields, increased extraction efficiency, and fewer impurities generation reason why it has been considered a green technology $[59,60]$.

This methodology has become an attractive alternative for extracting bioactive compounds such as ANC since it avoids thermal degradation and oxidation reactions because of the absence of light and oxygen [61]. To mention some examples, in our workgroup, Luna-Vital et al. [62] described the ANC extraction from purple corn pericarp by using HPE. The solvent chosen for the extraction was deionized water and the process was carried out at a temperature of $50{ }^{\circ} \mathrm{C}$ for $5 \mathrm{~min}$ at $10.34 \mathrm{MPa}$ of pressure. The extract was obtained successfully containing: C3G (45.8\%), cyanidin-3-(6'-malonylglucoside) (C3G-Mal) $(17.2 \%)$, a condensed form of flavanol-ANC (16.8\%), peonidin-3-O-glucoside (P3G) (9.3\%), peonidin-3-(6'-malonylglucoside) (P3G-Mal) (3.1\%), pelargonidin-3-(6'-malonylglucoside) (Pr3G-Mal) (2.4\%), and pelargonidin-3-O-glucoside (Pr3G) $(2.0 \%)$. However, ANC were not the unique components of this extract since several phenolic acids were also extracted, such as ferulic, protocatechuic, caffeic, chlorogenic, and gallic acids [63]. Putnik et al. [64] evaluated the performance of the high hydrostatic pressure extraction (HHPE) on the recovery of ANC from the grape skin pomace extracts under moderate temperatures. In this case, two solvents were used (ethanol and methanol), the compression fluid was propylene glycol, and the conditions of the extraction process were the following: 300, 400 , and $500 \mathrm{MPa}$ of pressure for 3, 6.5, and $10 \mathrm{~min}$ at 22, 26, and $30{ }^{\circ} \mathrm{C}$. The authors obtained, mainly, malvidin derivatives in two forms: malvidin-3-glucoside $(2.33 \mathrm{mg} / \mathrm{g})$ and malvidin-3-O-(6-O-acetyl)-glucoside $(0.83 \mathrm{mg} / \mathrm{g})$, representing $55.77 \%$ of overall ANC content. Followed by malvidin-3-O-(6-O-coumaroyl)-glucoside $(0.66 \mathrm{mg} / \mathrm{g})$ being $11.65 \%$, 
the remaining ANC were found in amounts lower than $0.5 \mathrm{mg}$. Once analyzed the applied parameters, the ideal settings for the process were pressure $268.44 \mathrm{MPa}$, extraction time $3.39 \mathrm{~min}$, and temperature $29.48^{\circ} \mathrm{C}$.

Haining and Yongkun [65] had the purpose of evaluating the influence of HHPE on the extraction of blueberry pomace ANC. The pressurizing fluid used was dioctyl sebacate, and the chosen solvents were ethanol and hydrochloric acid. The extraction process was carried out under different pressures (100 and $600 \mathrm{MPa}$ ) and holding times (5 and $30 \mathrm{~min}$ ) at room temperature. According to their optimization model, the significant extraction parameters were a liquid-solid ratio of $41 \mathrm{~mL} / \mathrm{g}$, ethanol concentration of $63 \%$, and extraction pressure of $443 \mathrm{MPa}$. The non-significant parameters such as hydrochloric acid concentration, holding time, and extraction cycles were fixed at $0.185 \%, 5 \mathrm{~min}$, and 1 cycle, respectively. At the optimal HHPE conditions, $107.9 \mathrm{mg} / 100 \mathrm{~g}$ of ANC were obtained, and 10 ANC were identified, being malvidin-3-galactoside and malvidin-3-glucoside the main ones.

\subsection{Supercritical Fluid Extraction (SFE)}

Supercritical fluid extraction (SFE) is a process used for separating one component, named the extractant, from another known as the matrix, using supercritical fluids as the extracting solvent [66]. The conditions of these fluids are above their critical point of pressure and temperature, their density is similar to liquids, their viscosity is comparable to gases, and their diffusivity is between both gases and liquids [67]. The main advantage of a supercritical fluid is that its density can be modified by changing its pressure and temperature. The properties mentioned earlier allow supercritical fluids to penetrate deeper and faster to solid matrices because they diffuse easily through them $[67,68]$.

Carbon dioxide $\left(\mathrm{CO}_{2}\right)$ is the most commonly used solvent due to its low cost, safety, and moderate critical temperature $\left(31.2{ }^{\circ} \mathrm{C}\right)$ that enables the preservation of bioactive compounds in extracts $[67,69]$.

Other remarkable advantages in comparison with standard extraction techniques are the use of solvents generally recognized as safe (GRAS), lower extraction times, increased yields meaning higher efficiency of the extraction process, and the option of direct coupling with analytical chromatographic techniques such as gas chromatography (GC) or supercritical fluid chromatography (SFC) [68]. Jiao and Kermanshahi [70] obtained ANC extracts from Haskap berry (Lonicera caerulea) pulp by SFE. Likewise, the authors carried out the extraction of ANC by the conventional method using water, intending to compare the yields obtained. A relevant aspect of this work was the combination of water and $\mathrm{CO}_{2}$. The highest total ANC yield (52.7\%) from berry pulp paste using $\mathrm{CO}_{2}$ was achieved using $45 \mathrm{MPa}, 65^{\circ} \mathrm{C}, 5.4 \mathrm{~g}$ water to $3.2 \mathrm{~g}$ paste, $15 \mathrm{~min}$ static, and $20 \mathrm{~min}$ dynamic time. In conclusion, compared with conventional extraction, using $\mathrm{CO}_{2}$ as solvent and water use as co-solvent offered higher ANC extraction efficiency ( $52.7 \%$ vs. $38.3 \%$ ).

The recent work conducted by Idham et al. [71] aimed to evaluate the effects of different particle sizes, flow rates, and modified ratios on the extraction yield and ANC content of Roselle (Hibiscus sabdariffa) by using the supercritical carbon dioxide $\left(\mathrm{SC}^{-} \mathrm{CO}_{2}\right)$ method. The pressure and temperature were kept constant at $10 \mathrm{MPa}$ and $70{ }^{\circ} \mathrm{C}$ respectively, and $75 \%$ ethanol was used as a modifier. Different solvent flow rates were studied: $4 \mathrm{~mL} / \mathrm{min}$, $5 \mathrm{~mL} / \mathrm{min}$, and $6 \mathrm{~mL} / \mathrm{min}$. Three different ground dried Roselle sizes were used: 200-355 $\mu \mathrm{m}$, $355-500 \mu \mathrm{m}$, and 500-710 $\mu \mathrm{m}$. Finally, three percentages of modifiers ratios were compared: $5 \%, 7.5 \%$, and $10 \%$. The effect of these three parameters showed different results of overall extraction yield and total anthocyanin content (TAC), demonstrating that these conditions are key to obtain the highest ANC concentration. The optimal parameters that allowed reaching the highest ANC concentration were extraction time of $120 \mathrm{~min}$, flow rate of $4 \mathrm{~mL} / \mathrm{min}$ obtaining a TAC of $5 \mathrm{mg}$ equivalents of C3G (EC3G)/L, particle size of 200-355 $\mu \mathrm{m}$ showing a TAC of $4.95 \times 10^{4} \mathrm{mg}$ EC3G/L, and a $10 \%$ of modifier ratio obtaining a TAC of $3.84 \times 10^{4} \mathrm{mg}$ EC3G/L. A summary of the primary outcomes from reported industrial extraction technologies of natural colorants is presented in Table 1. 
Table 1. Main outcomes from reported industrial extraction technologies of natural colorants.

Extraction Technology

Main Outcomes

Aqueous extraction of phenolic compounds extracted from wheat bran. The best conditions were $20 \mathrm{~V} / \mathrm{min}, 80^{\circ} \mathrm{C}, 10 \mathrm{~min}$ holding time to obtain $3150 \mathrm{mg} / \mathrm{kg}$ of phenolics and $82 \%$ antioxidant capacity.

Aqueous extraction of ANC with a yield $>80 \%$ from blue potato. Maximum recovery at $15 \mathrm{~V} / 90{ }^{\circ} \mathrm{C} / 10 \mathrm{~min}$.

Dark purple ANC were extracted from black rice bran with a higher yield (20.63\%) using $\mathrm{OH}$ compared with steam extraction. Conditions used at $30 \%$ and $40 \%$ moisture and $100-200 \mathrm{~V} / \mathrm{cm}\left(105{ }^{\circ} \mathrm{C}, 1 \mathrm{~min}\right)$.

Polyphenols extraction was accelerated with $\mathrm{OH}$ due to higher cell wall disruption. Higher yield (36\%) was achieved with $400 \mathrm{~V} / \mathrm{cm}$ with $30 \%$ ethanol-water.

Ethanol-water polyphenolic extracts were obtained from vine pruning residue. At $840 \mathrm{~V} / \mathrm{cm}, 80{ }^{\circ} \mathrm{C}$ and 60 min extraction, antioxidant, antimicrobial and anticancer activity were observed.

ANC have a high rate of degradation after $\mathrm{OH}$ application in blueberry pulp.

$\mathrm{OH}$ treatment was used on fungal red colorant in a beverage model system. Pigment degradation of $33 \%$ was observed with $\mathrm{OH}$ compared with $23 \%$ with a conventional method.

\section{$\mathrm{OH}$, and microwave-assisted extraction}

A response surface model was used to obtain the optimal values for ANC extraction using PEF. Optimal extraction (166 mg ANC) was found at $15.08 \mathrm{kV}$ and four pulses.

PEF was applied as pretreatment induced cell permeabilization and higher ANC yield. Maximum recovery $(65.8 \mathrm{mg} / 100 \mathrm{~g}$ ANC) was achieved at $3.4 \mathrm{kV} / \mathrm{cm}, 105 \mathrm{~ms}$ pulses, $40^{\circ} \mathrm{C}$, and $480 \mathrm{~s}$ processing time.

PEF treatment allow a "cold" extraction at low temperature $\left(30^{\circ} \mathrm{C}\right)$ with $95 \%$ yield and $10 \%$ colorant degradation. The conditions used were: $0.375-1.500 \mathrm{kV} / \mathrm{cm} ; 120$ pulses $(100 \mathrm{~ms}), 30-80{ }^{\circ} \mathrm{C}$.

PEF-assisted extraction of astaxanthin from Haematococcus pluvialis was performed at $0.2-1 \mathrm{kV} / \mathrm{cm}, 10-80$ pulses of $5 \mathrm{~ms}$ for $6 \mathrm{~h}$. Methanol and ethanol improved the extraction. A further aqueous incubation was necessary to recover the colorant.

Cell permeabilization caused by PEF pretreatment, allows nearly $100 \%$ b-phycoerythrin extraction from the alga Porphyridium cruentum. For this experiment, $10-50$ pulses of $3 \mu \mathrm{s}$ at electric field $2-10 \mathrm{kV} / \mathrm{cm}$, room temperature were used.

PEF was used to increase the stability of chlorophyll previously extracted with ethanol from Spinacia oleracea $\mathrm{L}$. The maximum recovery was observed at $26.7 \mathrm{kV} / \mathrm{cm}, 35^{\circ} \mathrm{C}$ and $0.32 \mathrm{~ms}$. 


\section{Technological Properties of Natural Food Colorants in Food Systems}

Several food colorants have been isolated from diverse sources to be applied in food systems. An overview of some of the most important food systems in which natural colorants are applied is presented in Figure 2.

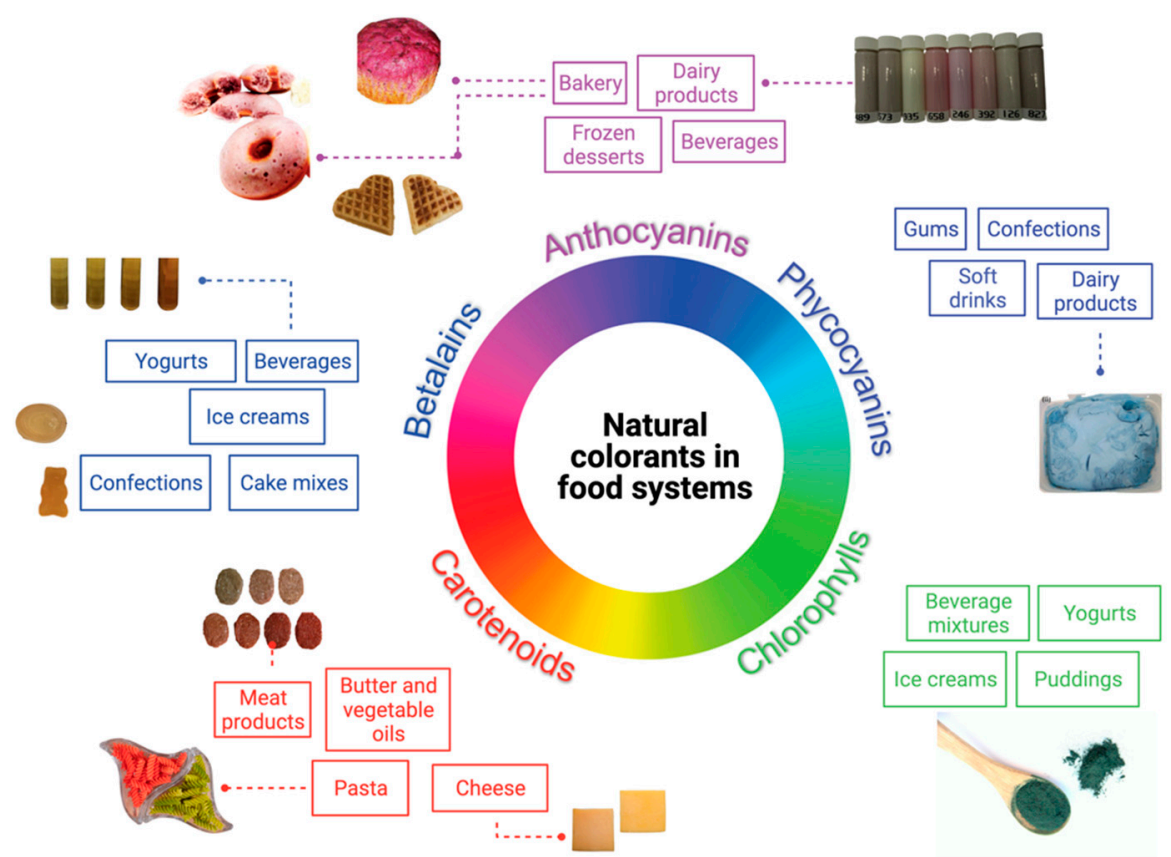

Figure 2. Natural colorants in food systems. Figures reprinted from Abdel-Moemin et al. [73], Amjadi et al. [74], Carballo et al. [75], da Silva et al. [76], de Amarante et al. [77], Freitas-Sá et al. [78], Jiménez-López et al. [79], Rodríguez-Sánchez et al. [34], Sharma et al. [80] with permission of Elsevier, MDPI A. G., or applicable society copyright owner.

\subsection{Bakery Products}

Purified colorants or plant extracts have been used to improve bakery products' nutritional properties without a major sensory impact. As such, Abdel-Moemin et al. [73] reported an enhanced chemical composition and high overall liking scores from cupcakes added with $20 \mathrm{~g}$ Roselle (Hibiscus sabdariffa L.) calyces extract/100 g cupcake, commonly used in the preparation of beverages. This functional extract was prepared with dry calyces to produce a fine powder $(0.55 \mathrm{~mm})$ mixed with water and then boiled for $1 \mathrm{~h}\left(80^{\circ} \mathrm{C}\right)$. The formulated cupcakes showed lower total carbohydrates $(-11.28 \%)$ and lipids $(-16.48 \%)$, while higher dietary fiber $(126.18 \%$ ) and ash (179.68\%) than the control cupcakes (without Roselle). Moreover, Roselle-added cupcakes retained $77 \%$ of the total ANC content from the dry calyces ( $435 \mathrm{mg} / 100 \mathrm{~g}$ cyanidin-3-glucoside), potentially providing up to 32-fold the minimum daily intake from Americans (12.5-215 mg). Although the resulting cupcakes displayed a crust and crumb pink color due to surface Maillard reactions developed during the baking process $\left(175^{\circ} \mathrm{C}\right.$ for $\left.20 \mathrm{~min}\right)$, no differences $(p>0.05)$ were found for the sensory evaluation of the color, appearance, texture, taste, volume, and aroma compared to control cupcakes, but received a lower liking.

Jiménez-López et al. [79] assessed the feasibility of a C3G extract from Arbutus unedo L. fruits to be incorporated into wafers. An optimized heat-assisted extraction was used to obtain an antioxidant C3G-rich extract with antioxidant potential (2,2-diphenyl-1picrylhydrazyl or DPPH half-maximal effective concentration, $\mathrm{EC}_{50}: 295 \mu \mathrm{g} / \mathrm{mL}$ and $\beta$-carotene $\mathrm{EC}_{50}: 901 \mu \mathrm{g} / \mathrm{mL}$ ) with anti-bacterial properties (Salmonella enteritidis minimum inhibitory concentration (MIC): $150 \mu \mathrm{g} / \mathrm{mL}$; Salmonella typhimurium minimum bactericidal concentration (MBC): $200 \mu \mathrm{g} / \mathrm{mL}$ ). The extract exhibited the highest stability at $\mathrm{T}<20^{\circ} \mathrm{C}$ and $\mathrm{pH}>3.5$. When added to wafers, the prepared product showed a golden color, higher 
sucrose amount, increased concentrations of fatty acids (palmitic, stearic, and linoleic acids), and improved antioxidant capacity compared to the untreated wafers.

Fruit and vegetable waste can also be a source of colorants. Tomato waste was employed as a lycopene source to be used in cakes and cookies [26]. Lycopene from tomato waste (fibrous pulp without peel and seeds) containing $654.8 \mathrm{mg} / 100$ total carotenoids and $300.85 \mathrm{mg} / 100 \mathrm{~g}$ lycopene. Oil from the cake's formula and butter from the cookies' ingredients was replaced with 1\%,3\%, and 5\% lycopene, and the resulting products were evaluated. Lycopene-containing cakes showed a dose-dependent volume increase, higher $\mathrm{DPPH}$ inhibition, and increased crust and crumb' lightness, but only $5 \%$ formulation showed a higher volume than control cakes (without lycopene). Sensory evaluation of the cakes showed significant differences in crust and crumb's color and texture (cakes were perceived as more yellow and redness than control cakes). Still, no differences were found among panelists for taste, odor, and overall acceptability. The same outcomes were found for the lycopene-added cookies.

Beetroot (Beta vulgaris L.) pomace was used as a source of betacyanin and betacyaninderivatives extract, further encapsulated and used in pseudocereals (amaranth, buckwheat, and quinoa)-enriched wheat einkorn (Triticum monococcum) water biscuits. Independently of the pseudo-cereal, all extract-added biscuits showed a dose-dependent betanin, isobetanin, and betanin-derivatives increase (5.7\%, 10.4\%, 14.9\%, and 10.8\% extract addition) compared to control biscuits. Buckwheat (Fagopyrum esculentum) biscuits displayed the highest total phenolic compounds (TPC) content ( $2500 \mathrm{mg}$ gallic acid equivalents or GAE/kg dry matter, DM), ferric ion reducing antioxidant power (FRAP), and 2,2'-azino(bis-ethylbenzothiazoline-6-sulfonic acid) (ABTS) values ( 18 and 14 mmol Trolox equivalents / kg DM, respectively). Quinoa (Chenopodium quinoa) biscuits showed the highest furosine contents ( $275 \mathrm{mg} / 100 \mathrm{~g}$ protein), suggesting a lower ability of the encapsulated extract to prevent heat damage for this ingredient.

Rubus ulmifolius Schott has been investigated as a novel source of food colorants incorporated in bakery products [76]. Heat-assisted extraction was conducted to produce an ANC-rich extract, and the main identified ANC (cyanidin-O-di-hexoside, C3G, Pr3G, cyanidin-3-O-xyloside, and cyanidin-3-O-dioxayl-glucoside) were used as responses for a Response Surface Analysis (RSM). The extract contained $33 \mathrm{mg}$ ANC/g extract and showed a red-burgundy color. When added to donuts, lightness and yellowness $\left(\mathrm{b}^{*}\right)$ decreased ( -24.34 to $25.97 \%$ and -44.67 to $48 \%$, respectively), but the redness was increased ( +109 to $338.67 \%$ ) when compared to control donuts. The formulated donuts also showed lower carbohydrates and energy value contents, higher free sugars values $(p<0.01)$, and no differences were found for the free fatty acids content.

Albuquerque et al. [81] optimized a heat- and ultrasound-assisted ANC-rich extract from jabuticaba (Myrciaria jaboticaba (Vell.) Berg) epicarp as a natural colorant to be used in the manufacturing of french macarons. Heat-assisted extraction proved to be the most successful extraction using delphinidin-3-O-glucoside and cyanidin-3-O-glucoside levels as responses. The resulting macarons $\left(13 \mathrm{~min}\right.$ at $130{ }^{\circ} \mathrm{C}$, conventional oven) showed lightness $\left(\mathrm{L}^{*}\right)$, redness $\left(\mathrm{a}^{*}\right)$, and yellowness $\left(\mathrm{b}^{*}\right)$ preservation (overall $-0.05 \%$ change) up to six days of storage, while low glucose, fructose, and sucrose changes were observed during the same evaluation period.

Several reports have informed the potential of whole food products for coloring or technological properties. For instance, colored tubers such as purple-fleshed sweet potato (I. batatas L.)-colored flours were used in biscuit formulations [82]. Although no colorants were mainly extracted from the raw materials, the flour contained high TPC (80.89 mg GAE/100 g) and TAC (38.90 mg C3G equivalents/100 g). Despite 67.24\% TPC and $27.79 \%$ TAC were retained in the biscuits, respectively, due to compound losses during the baking process $\left(160{ }^{\circ} \mathrm{C}, 20 \mathrm{~min}\right.$, electric oven), potato-supplemented biscuits exhibited TPC: 2.27- and TAC: 10.82-fold increase, compared to control biscuits. The enhanced nutritional composition yielded high FRAP and DPPH levels. 
Similarly, Croitoru et al. [83] partially replaced wheat flour with black rice flour to manufacture muffins. The $50 \%$ and $100 \%$ black rice formulations showed an outstanding TPC, total flavonoids (TF), and TAC contents, compared to wheat-only muffins, which was reflected on the antioxidant capacity (up to four-times compared to control muffins). No differences were found $(p>0.05)$ for the overall acceptability of the novel muffins, showing a beneficial potential of colored ingredients to improve the nutritional composition without a negative impact on the sensory parameters.

In summary, natural food-colorants can be used to positively impact the crust and crumb's color from several bakery products, producing a pleasant flavor and interesting health-added benefits, mainly antioxidant properties. However, most researchers have not evaluated these properties at in vivo level but in vitro tests using assays that hardly mimics the antioxidant levels found in organisms [84]. Moreover, more research is needed evaluating the impact of the processing conditions at which bakery products are subjected (high temperature, low moisture, among others) in the dyeing properties of natural foodcolorants. Hence, encapsulation might be a suitable technological advantage using proper wall materials allowing colorants to exert their function but also preserving their healthy characteristics.

\subsection{Beverages}

Consumers usually associate the beverages' colors from natural sources such as yellow for lemons or red for strawberries, to mention some examples. Hence, color is a critical feature with the potential to enhance their appeal and acceptability [85].

Most beverages require colorants since food processing contributes to substantial color loss. Thus, various food and non-food natural sources can be used as materials to isolate functional colorants, retaining stability and shelf life. Commercial purple carrot ANC $(0.025 \%)$ combined with green tea extract rich in epigallocatechin gallate (EGCG) showed high stability to ANC degradation and delayed half-life of ANC from 2.62 days to 6.73 days in first-order reaction kinetics [13]. These protective effects provided by the green tea extract are a consequence of EGCG protection over ascorbic acid condensation or oxidation by hydrogen peroxide, allowing even higher stability at increasing temperatures (from $25^{\circ} \mathrm{C}$ to $40^{\circ} \mathrm{C}$ ).

Cyclodextrins are cyclic molecules used as encapsulants of flavors, vitamins, colorants, and ingredients, increasing their shelf-life and promoting controlled release for technological or physiological features such as improved bioaccessibility, and antioxidant capacity [86]. Particularly for beverages, it can be used for co-pigmentation purposes, stabilizing highly degradable pigments. For example, black bean coats anthocyanin-rich extracts were stabilized with $2 \% \beta$-cyclodextrins to manufacture a model sport beverage [87]. The extracts were prepared using coats from two black beans (Phaseolus vulgaris L.) varieties ("Negro Otomi" and "Idaho" cultivars) after an optimized pH-adjusted aqueous ANC extraction $\left(40^{\circ} \mathrm{C}\right.$ for $\left.4 \mathrm{~h}\right)$. High destruction values were obtained for the ANC powders and coat extracts (9.51-119.93 days), but encapsulation with $\beta$-cyclodextrin retarded their degradation (up to 43 months). $\beta$-Cyclodextrin widely used as additive to protect colorants from environmental conditions. The addition of the $\beta$-cyclodextrin-encapsulated extracts to a sports beverage extended ANC half-life (up to 13 months) and reduced color differences under darkness at $4{ }^{\circ} \mathrm{C}$.

Beverage models can be used to evaluate the stability of natural colorants at varying $\mathrm{pH}$, acidity, and other environmental conditions. Rodríguez-Sánchez et al. [34] evaluated pitaya (Stenocereus pruinosus) betaxanthins (betalain-type pigments) extracts in a model yellow beverage, obtaining a highly disperse chroma (21.38-87.78) and hue (53.9-87.8) values and several shades of yellow-orange. However, beverages pigmented with $5 \%$ pitaya juice were those with the most similar color to their commercial counterparts (color difference $\Delta \mathrm{E}=9 \mathrm{vs}$. control beverage). Formulated beverages retained up to $75 \%$ of total betaxanthins during the first nine days of storage. The authors suggested the ability of this pigment to substitute synthetic yellow pigments in commercial beverages. 
Lobo et al. [88] encapsulated yellow bell pepper pigments with $\beta$-cyclodextrin and evaluated their stability in isotonic beverages ( $\mathrm{pH}: 2.9 ; 0.02 \%, 0.05 \%$, and $0.06 \%$ of extract addition). Lutein, zeaxanthin, $\alpha$-cryptoxanthin, $\alpha$-carotene, and $\beta$-carotene were the main carotenoids found. Extract-added beverages exhibited dose-dependent luminosity and redness increase but decreasing yellowness. No differences along time (21 days) were observed among the beverages for lightness, but yellowness significantly decreased $(p<0.05)$.

Soft-drink beverage models were assayed to evaluate the stability of a vacuumconcentrated colorant extracted from yellow-orange cactus (Opuntia ficus indica) [89]. The extract $(0.7 \% v / v)$ was added to soft drinks $(86 \mathrm{~g} / \mathrm{L}$ sucrose, $0.14 \mathrm{~g} / \mathrm{L}$ sodium benzoate, $0.18 \mathrm{~g} / \mathrm{L}$ potassium benzoate, $0.02 \mathrm{~g} / \mathrm{L}$ ascorbic acid, and $1.52 \mathrm{~g} / \mathrm{L}$ citric acid, among other components). Indicaxanthin was the main identified betaxanthin (concentration: 256.53-264.86 mg indicaxanthin equivalents $/ \mathrm{kg}$ ). First-order reactions were fitted for betaxanthin degradation in the soft-beverage models, where the beverages' $\mathrm{pH}(3.0)$ could influence the degradation as betaxanthin are stable at $\mathrm{pH}$ : 5.0. As suggested by the authors, this extract could also be used in chilled matrices such as yogurt and ice cream.

The yellow color is a very demanded pigment in the beverage industry, being carotenoids (bixin, lutein, and crocin), betalains (betaxanthins), flavonoids (carthamin), curcuminoids (curcumin), and riboflavins the most usual colorants [90]. An extensive evaluation of several yellow natural pigments (annatto from Bixa orellana L. seeds, gardenia yellow from Gardenia jasminoides Ellis, lutein from marigold flowers or Tagetes erecta L., curcumin from turmeric or Curcuma longa L., and safflower extract from Carthamus tinctorius L.) were evaluated in colored beverage model systems [91]. To simulate alcoholic and non-alcoholic beverages, McIlvaine buffer ( $\mathrm{pH}$ : 3.5, 5.5, and 7.5; concentrations: 0.001, 0.005, 0.01, 0.02, $0.03,0.05,0.10$, and $0.30 \% v / v)$ with or without ethanol $(15 \% v / v)$, were prepared. Gardenia, safflower, and curcumin exhibited the highest color intensity and the lowest turbidity level, whereas safflower showed the highest heat $\left(25,40,60\right.$, and $\left.80{ }^{\circ} \mathrm{C}\right)$ and light $\left(550 \mathrm{~W} / \mathrm{m}^{2}\right.$, $30{ }^{\circ} \mathrm{C}$ ) stability.

Cyanidin-rich or pelargonidin-rich purple corn extract-added model beverages were tested for stability with and without a flavone-rich extract [92]. The cyanidin-rich beverages were more stable than pelargonidin ones, but a 50\% increased half-life was obtained for both systems after adding the flavone extract. Together with their technological features, these extracts have also shown interesting biological properties in vitro and in vivo, playing a dual role in replacing artificial colorants and delivering potential health benefits [63]. Compared to extract-added-only beverages, the addition of alginate and zinc ions to these extracts protected ANC from degradation in a beverage model, improving ANC half-life (10.4 weeks), C3G concentration (7.5 weeks), and chroma (18.4 weeks) [62].

Gomes Rocha et al. [93] developed whey-based beverages containing ANC from jabuticaba (Plinia cauliflora) skins for protein beverages. Delphinidin-3-O-glucoside (D3G: $9.8 \mathrm{mg} / \mathrm{L})$ and C3G (198.9 mg/L) were identified in the jabuticaba extract. The highest whey-containing beverages $(4.0 \%$ and $6.0 \% \mathrm{w} / \mathrm{v})$ exhibited clearer colors, with no differences in $\mathrm{a}^{*}$ and chroma parameters. The red color was predominant in the beverages. All beverages contained the same $(p>0.05)$ ANC content $(1.4-1.5 \mathrm{mg} / 100 \mathrm{~g})$, but TPC and antioxidant capacity were whey dose dependent.

Jelly drinks were pigmented with encapsulated ANC pigments from purple sweet potato (Ipomoea batatas L.) cv. Ayamurasaki [94]. The resulting beverage stored at $5{ }^{\circ} \mathrm{C}$ without light exposure showed the smallest ANC and redness decreased after 30 days of storage, while its calculated shelf-life was estimated in 200 days.

Among alga-derived sources, Porphyridium aerugineum microalga-derived blue color has been used for acidic beverages. These pigments display pinkish-red or blue color extracted by cell breakage using water or buffered solutions, centrifugated, purified, and sterilized by microfiltration, spray-drying, or freeze-drying [95]. The blue color is stable at $\mathrm{pH}$ 4.0-5.0 for 1 month at room temperature or up to $40 \mathrm{~min}$ at $60^{\circ} \mathrm{C}$. It can be added to 
acidic non-heat treated carbonated beverages (Pepsi ${ }^{\circledR}$ ) or low-grade alcohol beverages (Bacardi Breezer $\left.{ }^{\circledR \circledR}\right)[1,95]$.

Concluding, beverages are one of the most suitable models for studying the natural food-colorants' shelf life since the aqueous media and processing conditions provide challenging conditions to test colorants' behavior. Since beverages have been used to promote the consumption of vegetables and fruits as their intake remain below the recommended levels in many countries [96], colorants are also used to prevent beverages' color loss during the thermal processing.

\subsection{Confectionery}

Confections belong to a very dynamic food industry sector with high demand for coloring agents. Several confections have been targeted as concerning due to cadmium and lead-based colors potentially causing brain glioma, urinary bladder and kidney tumors, or hypersensitivity [97].

Figs (Ficus carica) and blackthorns (Prunus spinosa L.) extracts were used to manufacture beijinho, a condensed milk-based confection, and doughnut icing [98]. Peels from $F$. carica and the epicarp of $P$. spinosa were freeze-dried, milled (20 mesh), and ultrasoundassisted extraction was conducted, using $100 \mathrm{~mL}$ of acidified solvent $(\mathrm{pH} 3$, citric acid). The peel was rich in cyanidin-3-rutinoside, while the blackthorns extracts were rich in cyanidin-3-rutinoside and peonidin-3-rutinoside. Both food products contained sucrose $>$ lactose $>$ fructose contents. Up to 21 fatty acids were identified in both foods, and palmitic acid was the most abundant (icing: $14 \%$; beijinhos: $10 \%$ ). Saturated fatty acids were the most relevant group $(75 \%)$, followed by monounsaturated. Blackthorn-added products displayed intense purple colors, and figs-added products exhibited light tones.

A betaxanthin-rich extract from pitaya (S. pruinosus) was used to produce yellow gummies, showing disperse chroma values depending on the juice or pulp concentration (10.6-15.6 and 10.6-13.2, respectively), with shading varying from yellow to orange. Half of the pigment was lost after 11 days at $40{ }^{\circ} \mathrm{C}$, and betaxanthins followed a first-order kinetic evolution [34]. Calcium alginate-encapsulated betalains from Opuntia ficus-indica (purple pulp) were added to gelatin-based gummies, and no differences in the color parameters (lightness, $\mathrm{a}^{*}$, and $\mathrm{b}^{*}$ ) were found after a 30 days-storage at $4{ }^{\circ} \mathrm{C}$ [99].

Saffron (Cocus sativus) and beetroot (Beta vulgaris L.) aqueous extracts were encapsulated in maltodextrin, gum arabic, modified starch, and chitosan and incorporated in a chewing gum system [100]. Modified starch and other ingredients were used as wall materials to protect target pigments in food systems [101]. The luminosity from the chew gums decreased along time $\left(25^{\circ} \mathrm{C}\right.$ and $40^{\circ} \mathrm{C}$ storage), whereas $\mathrm{a}^{*}$ almost disappeared after two-weeks' storage at $40^{\circ} \mathrm{C}$. However, gum arabic and modified starch proved to be the best color stability mixture independently of the extracts, displaying the highest $\mathrm{a}^{*}$ (for beetroot) and $b^{*}$ (for saffron) values.

Promising underutilized fruit products can be used as sources of varied colorants for the confection industry, despite a colorant not being extracted from these raw materials. Açaí (Euterpe oleracea Mart.) was evaluated for its coloring properties in a chewy candy model [102]. The resulting candies had lower $\mathrm{a}_{\mathrm{w}}$ and no differences were found for the hardness or the moisture content than non-added Açaí candies. Higher color acceptance $(4.34 \%)$ and the same texture evaluation were obtained for both non- and added-Açaí candies. Although the positive purchase intent was lower in the Açaí candies $(-42.86 \%)$, high uncertainty in the purchase intent $(166.7 \%)$ was observed in the Açaí testers, suggesting the potential of these candies to be acquired.

Dragees or hard-panning confections are elaborated by applying several layers of coating material such as saturated sugar syrup to produce a hard or crispy shell [103]. Most water-soluble pigments can be used in these confections, but as the panning syrup is prepared at temperatures higher than $80^{\circ} \mathrm{C}$ to prevent recrystallization of sugar, the tested pigments require to preserve most of its properties at these working conditions [104] Avelar et al. [105] explored the possibility of using by-products from Uvaia (Eugenia 
pyriformis), a native fruit from southeastern Brazil, as a low-cost coloring agent in hard panning confections. Coated confections exhibited the lowest $\mathrm{a}_{\mathrm{w}}$ and luminosity, but the highest $\mathrm{a}^{*}, \mathrm{~b}^{*}$, and hardness than fruit-based concentrate- and artificial colorant-added candies. The best appearance and color attributes were obtained for the Uvaia-added candies, but they displayed the lowest crispness (6.61 score vs. 6.77 and 7.16 for fruit-based and artificial colorants).

Several pigments can be used to color jelly gummies, confections composed of sugars, gelling agents (pectin, agar-agar, gum arabic, gelatin, among others) and food-grade acids (citric or tartaric acids). For the yellow shades, Carthamus (Carthamus tinctorius L.) has been used to provide a transparent appearance, but bright yellow can be reached using curcumin. However, these oily pigments need to be formulated using proper emulsion, suspensions, or encapsulation systems since curcumin exhibits poor stability [104]. For warmer color shades, carotenes can be applied to jelly gum from varied sources such as palm carotenes, resulting from the fungal fermentation of Blakeslea trispora, or those produced by the alga Dunaliella salina. Nonetheless, for another color, unconventional or underutilized fruit and vegetable sources can be used. Małgorzata et al. [106] reported the potential of black elderberry (Sambucus nigra L.) extracts prepared from their flowers and fruits as dyes to manufacture healthy jelly gum confections. ANC such as cyanidin-3$\mathrm{O}$-sambubioside-5-glucoside, cyanidin-3,5-diglucoside, cyanidin-3-O-sambubioside, and cyanidin-3-O-rutinoside were identified in the extracts. However, the flowers exhibit a rich polyphenolic profile governed by quercetin derivatives $(4.04 \mathrm{mg} / \mathrm{g}$ quercetin-3-rutinoside and $0.56 \mathrm{mg} / \mathrm{g}$ quercetin-3-glucoside $)$ and chlorogenic acid $(2.82 \mathrm{mg} / \mathrm{g})$. The designed jelly gummies showed high FRAP (597.46-849.58 $\mu \mathrm{mol}$ Trolox equivalents, TE/g), DPPH (68.23-90.11\% inhibition), and TPC (14.68-25.34 mg GAE/g).

Microalgae are an important source of natural pigments, containing macro and micronutrients with interesting biological properties that could add health benefits to natural colorants in confections [107]. For example, Genc Polat et al. [108] applied spray-dried encapsulated Nannochloropsis oculata microalga extract in white chocolate as a coloring agent. The obtained chocolate presented varied luminosity (61.6-78.0) and increased $a^{*}$ and hue compared to control chocolate samples. Although the alga-added samples showed lower scores for the appearance, texture, and smell, their values were not different $(p<0.05)$ than the control samples.

The red microalga genus Porphyridium has proven to be a source of fluorescent phycobiliproteins with pigment properties on confections. The red or pink colorant can be added to transparent lollipops made from sugar solutions or dry sugar-drop candies for cake decorations, exhibiting high stability at $60^{\circ} \mathrm{C}$ for $30 \mathrm{~min}$ and long shelf life at $\mathrm{pH} 6.0-7.0$ [1].

Last but not least, adding natural food-colorants to confection opens an opportunity to diversify the functional confectionery market, reaching traditional population targets such as children, to deliver health benefits in low sugar formulations with increased nutritional properties. Functional confectionery no only relies on adding isolated natural food-colorants, but also food by-products with demonstrated beneficial nutritional composition such as high dietary fiber and antioxidant compounds contents [109].

\subsection{Milk, Dairy, and Dairy-Like Products}

Similar to other food products, natural food-colorants can be added to milk and dairy products to restore the natural color potentially lost during processing and storage or to reduce the batch-to-batch variations. Moreover, colorants can intensify natural colors in case they are weak, provide color to colorless products, and produce acceptable and attractive products for consumers [8]. Several researchers have used natural colorants in milk and dairy products for several purposes, such as those described above.

Dairy food matrices are challenging since colorants might affect some of their textural properties. Natural colors are usually preferred for yogurts due to their heat stability during processing and can be easily labeled as "vegetable color". Some of the most common natural colorants used in yogurts are carmine from cochineal beetle (brilliant red 
color ranging from "strawberry" to "blackcurrant" color), annatto from Bixa orellana, ANCrich extracts from mulberry (Morus rubra), red color from strawberries, and orange color from the carrot addition to yogurt [110]. Betacyanin pigments extracted from Ayrampo (Opuntia soehrensii Britton and Rose) were used in 3\% fat yogurt as natural colorants. After an optimized extraction and purification, betacyanins showed first-order degradation kinetics when subjected to heat treatment $\left(80{ }^{\circ} \mathrm{C}\right.$ for $\left.90 \mathrm{~min}\right)$ at several $\mathrm{pHs}(3,4$, and 5) [111]. However, an average half-life of 272 days was obtained when betacyanins were stored at $4{ }^{\circ} \mathrm{C}$, whereas a half-life of 26 days was shown for $25^{\circ} \mathrm{C}$ storage. The application of this extract in yogurt (32-192 $\mu \mathrm{g}$ betacyanin/100 g yogurt) resulted in the lowest $\Delta \mathrm{E}$ at $96 \mu \mathrm{g}$ betacyanin $/ 100 \mathrm{~g}$, while greater values exhibited decreased $\mathrm{L}^{*}$ values and higher $\Delta \mathrm{E}$, compared to commercial yogurt. Color stability during storage (up to 5 weeks) was similar to synthetic colorant Red no. $40(>94 \%)$, and even higher than red beet extracts also applied to the same yogurts.

For example, natural curcumin (E100) was applied to a hydrophilic matrix represented by yogurt [112]. As curcumin exhibits poor water solubility and susceptibility to alkaline conditions, light, oxidation, and heat, encapsulation was also assayed. Diverse color changes (closer to organ color) were obtained from the formulations (4.75-5.25\%), where water, protein, ash, galactose, energy, and $b^{*}$ were the dominant parameters having a discriminant effect among the samples. Stored yogurts for seven days displayed $a^{*}$ reduction, but overall color could be maintained a long time.

Pires et al. [113] incorporated natural colorants extracted from flowers such as Dahlia mignon, Rosa damascena "Alexandria", Rosa gallica "Francesca", and Centaurea cyanus L. Centaurea contained the highest amount of TAC $(26 \mu \mathrm{g} / \mathrm{g})$, and cyanidin-3,5-di-O-glucoside and cyanidin-3-O-(6"'-malonylglucoside)-5-O-glucoside were the most abundant ANC. Except for the galactose contents (Centaurea was the highest), there were no differences $(p>0.05)$ for the water, fat, protein, ash, carbohydrates, lactose, or energy contents and these parameters did not change during the seven-day storage of the yogurts. Furthermore, compared to a commercial colorant (E163), there were no differences in $\mathrm{L}^{*}, \mathrm{a}^{*}, \mathrm{~b}^{*}$, or $\mathrm{pH}$ values.

Jabuticaba (Myrciaria jaboticaba (Vell) O. Berg) and jamelão (Syzygium cumini L. Skeels) peel powders were testes as colorants in yogurts [78]. Test consumers (106) participated in a matching task associating the manufactured yogurts with fruit flavor variants, and high dependence $(p<0.01)$ between color and flavors of yogurts was found. For the sensory evaluation, Jabuticaba-added yogurts received the best appearance (6.6-6.8), flavor (6.9), and overall liking (6.8) scores among the flavored-yogurts. However, all values were lower $(p<0.05)$ than the not-colored yogurt except for the appearance.

Benchikh et al. [114] optimized ANC extraction from strawberries (Fragaria ananassa) using the response surface methodology and applied the obtained colorant to yogurt. ANC's optimal conditions were obtained for agitation speed of $586 \mathrm{rpm}$, and sample to solvent ratio of $1.26 \mathrm{~g} / 40 \mathrm{~mL}$, obtaining TAC: $38.04 \mathrm{mg} \mathrm{C3G}$ equivalents $/ 100 \mathrm{~g}$ fresh weight, and $21.22 \mu \mathrm{g}$ ascorbic acid equivalents $/ 100 \mathrm{~g}$ yogurt for the antioxidant capacity (DPPH). The yogurts contained 10-40 $\mu \mathrm{g} / 100 \mathrm{~g}$ TAC and a remaining red color after the manufacturing process ( $\mathrm{pH}: 4.6,4^{\circ} \mathrm{C}$ ), but no shelf-life evaluations were conducted.

The color stability of betalain- and ANC-rich extracts in yogurt-like fermented soy from several sources such as red beetroot (Beta vulgaris L.), opuntia (Opuntia stricta), Roselle (Hibiscus sabdariffa), and radish (Raphanus sativus L.) was evaluated [115]. The authors showed that red beetroot contained the highest amount of betacyanins ( $20.1 \mathrm{mg}$ equivalents of betacyanin/L) and betaxanthins ( $4.27 \mathrm{mg}$ equivalents of indicaxanthin/L), while Roselle the highest quantity of ANC $(13.01 \mathrm{~g} / \mathrm{L})$. The extracts were applied in an encapsulated and non-encapsulated form (liposomes of soybean lecithin), showing high retention of the extracts after 21 storage days, being Roselle and red radish, the most stable ones compared to untreated yogurt samples. The beetroot-added yogurts exhibited the highest a* values, followed by red radish, opuntia, and Roselle.

Flavored fermented milk was prepared with a microencapsulated extracted pigment (Canthaxanthin), a carotenoid-type colorant from Dietzia natronolimnaea HS-1 bacteria, 
which is permitted to be used in milk products up to $15 \mathrm{mg} / \mathrm{L}$ [116]. Fermented milk beverages showed significant reductions $(p<0.05)$ in the antioxidant capacity (DPPH method) after 7,14 , and 21 days $(-40.16 \%,-49.61 \%$, and $-52.83 \%$, respectively). Regarding the color parameters, $\mathrm{b}^{*}$ and $\mathrm{L}^{*}$ increased during 21 -days storage, but no changes $(p<0.05)$ were reported for the color difference $(\Delta \mathrm{E})$. Microcapsules-added yogurts also exhibited a decrease in viscosity values, but this was attributed to capsule disintegration during storage and hydrogen bond formation between protonated carboxyl groups from alginate due to low $\mathrm{pH}$.

Other dairy products have been formulated with natural colorants. Montibeller [117] assessed an ANC-rich extract from grape skin (Cabernet Sauvignon) on kefir, obtaining a decreased $\mathrm{pH}$ (up to $\sim 4.55$ ), increased acidity (up to $\sim 0.080 \%$ citric acid), and low total soluble solids ( $\sim 7.6^{\circ}$ Brix) after the addition of the extract in a 16-days evaluation of kefir performance. At the same time, $\mathrm{L}^{*}$ and $\mathrm{b}^{*}$ values increased (reaching 96.6 and 5.1, respectively), and $\mathrm{a}^{*}$ progressively decreased to $\sim 1.2$. The storage time affected ANC retentions, but high values were obtained for peonidin-3-glucoside and delphinidin-3-O$p$-coumarylglucoside ( $77-88 \%)$. The authors suggested that the ANC-formulated kefir showed similar physical properties compared natural kefir without additives.

Ice creams are popular dairy or dairy-like frozen desserts at neutral $\mathrm{pH}$, sometimes formulated with milk fat, milk proteins, fruits, and flavors. Stabilization of color in ice creams is still a problem that merits further research since some of them must be stabilized with polysorbate, negatively affecting the formation of overrun, one of the most desired attributes of ice creams [118]. The most common colorants used in ice cream are curcumin (intense lemon shade), Carthamus (bright yellow with slight greenish shade), $\beta$-carotenes (orange-yellow hues, preferred for vanilla-flavored products), annatto (yellow shades), beetroot (pink-red color), lycopene (red color), and chlorophylls or copper-chlorophylls (yellowish-green and bright green colors, respectively) [119].

Singo and Beswa [120] reported the impact of aqueous Roselle (Hibiscus sabdariffa) extracts $(5 \%, 10 \%, 15 \%$, and $20 \% v / v)$ on selected quality characteristics of ice cream. The extracts exhibited a direct relationship between the dose increase and $\mathrm{L}^{*}, \mathrm{~b}^{*}$, and whiteness index, while $\mathrm{a}^{*}$ progressively augmented up to 1.50 for the highest Roselle concentration. All Roselle-added ice creams showed lower $\mathrm{L}^{*}, \mathrm{a}^{*}$, and whiteness index values. Compared to a commercial vanilla-flavored ice cream control, overrun and melting rate values were higher $(p<0.05)(25.71-139.28 \%$ and $85.71-228.57 \%$, respectively), but viscosity and $\mathrm{pH}$ were lower for the highest Roselle concentrations $(p<0.05,-2.97 \%$ to $-3.13 \% ;-4 \%$ to -6.22 , respectively). The lowest Roselle-formulated ice creams (5\% and $10 \%$ ) showed no differences against the control in the sweetness and gummy taste evaluations. The authors considered that Roselle formula above $5 \% v / v$ would produce less viscous, high melting rate, unpopular color, and undesirable characteristics.

Durmaz et al. [121] used spray-dried microalga (Nannochloropsis oculata, Porphyridium cruentum, and Diacronema vilkianum) as coloring agents for ice cream $(0.1,0.2$, and $0.3 \mathrm{~g} / 100 \mathrm{~g}$ ice cream). The main pigments found in the spray-dried products were carotenoids (0.40-0.77 mg/g dry weight), chlorophyll a $(1.06-4.76 \mathrm{mg} / \mathrm{g}$ dry weight), and ANC (2.34-23.96 mg C3G/ kg). Compared to control ice cream, apparent viscosity decreased once added the microalga extracts, showing a resemblance to Newtonian fluids, being $P$. cruentum-added ice creams those with the most advantageous behavior as this microalga contains several carbohydrates such as cell storage polymers (starch derivatives), lipopolysaccharides, and extracellular polysaccharides. Ice creams enriched with P. cruentum displayed pinkish color, and the two other alga species showed a greenish color. Luminosity was not affected by type and concentration, while $b^{*}$ values increased together with alga concentration. Alga addition negatively impacted melting behavior, but the authors suggested the potential of optimization studies improving the ice cream composition and using bulking agents to overcome this situation.

Aqueous and ethanolic/methanolic betacyanin extracts from red pitahaya (Hylocereus polyrhizus) were applied as a colorant in ice creams [122]. The highest betacyanin yields 
(up to $18 \%$ ) were acquired by adding pectinase $(1.5 \%$ and $2.0 \% \mathrm{v} / \mathrm{v})$ in the $95 \%$ ethanol extractions. During 21-day storage, betacyanins concentrations increased $(\sim 0.02 \%)$, and no significant color changes were found $(p>0.05)$. Betacyanin-supplemented ice creams exhibited the highest free radical scavenging activities (DPPH: 50-57\%).

Using colorants in cheese is also a common practice. Natural colorants are preferred mainly for their health benefits, providing additional properties such as antioxidant, antimicrobial, and surface-active activity to colored cheese products [4]. The main colorant used in cheese and butter is annatto, but for the cheese industry, the colorant is mainly composed of norbixin, responsible for imparting yellow/orange color to cheddar cheese [123]. Other usual colorants used in cheese are carminic acid and ANC, paprika oleoresin, vegetable carbon, chlorophylls and chlorophyllin, and curcumin [80]. Saffron (Crocus sativus L.) was used as a colorant for fresh ovine cheese starting from a concentrated extract $(1000 \mathrm{mg} / \mathrm{L})$ and added to $2 \mathrm{~L}$ pasteurized ovine milk [124]. No differences were found for all treatments regarding moisture, total protein, salt, and fat contents $(p>0.05)$, saffronadded cheeses exhibited the lowest $\mathrm{pH}$ levels (4.13-4.36) and highest antioxidant capacity values (23.84-25.97\% RSA). Saffron did not affect $L^{*}$, but $a^{*}$ and $b^{*}$ values were higher compared to control cheeses. The $50 \mathrm{mg} / \mathrm{L}$ saffron-supplemented cheese was evaluated equally to control cheeses, while the highest saffron concentration negatively affected the sensory scores.

Sea buckthorn (Hippophae rhamnoides L.) fruit extracts were also assayed as colorants for cream cheese [125]. Chlorophylls (2.79 mg/L chlorophyll $a ; 4.73 \mathrm{mg} / \mathrm{L}$ chlorophyll $b)$ ), carotenoids (8.27 mg/L total carotenoids), and TPC (1842.86 mg/100 g dry weight) were the major quantified pigments and polyphenols from the fruits' extracts. The addition of the extracts increased (2.04\%) the average organoleptic score, decreased dynamic viscosity (up to $11258 \mathrm{mPa} \cdot \mathrm{s}$ ), and showed the same total viable count $\left(4 \times 10^{2} \mathrm{cfu} / \mathrm{g}\right.$ ) compared to $0.01 \%$ tartrazine-added cheese.

Lastly, dairy products are ideal complex food systems that can be used to test natural food-colorants properties since phenolics, and other components form interactions potentially reducing their abundance and health benefits. Hence, yogurt is one of the most tested dairy products to particularly test coloring properties and antioxidant capacity of their bioactive compounds [126]. Carotenoid and ANC are the most common colorant types used in dairy products, but the blue pigment provided by phycocyanobilins and the $\mathrm{pH}$-stable shades given by betacyanins have opened an opportunity to these chemical groups to be more widely incorporated.

\subsection{Meat and Meat Products}

Curing is a highly valued process in the meat industry since it prevents Clostridium botulinum growth and development. Concerns about this process' carcinogenic and toxic effects of nitrosamines as a result of the nitrite and nitrates have stimulated research in other colorants not only for a generation of a stable color but to reduce the need of using curing salts. In this sense, it has been found specific applications for plant-derived colorants such as beetroot (Beta vulgaris L.: red betacyanins and yellow betaxanthins), paprika (Capsicum annuum L.: red color), tomato (Solanum lycopersicum: lycopene); and microbial pigments like pigments from Monascus purpureus (purple color) [127].

Slightly colored meat products (e.g., pork and turkey) are some of the most routinely used food systems to evaluate the pigment properties of natural colorants. Several researchers have focused on the assessment of these pigments in sausages, widely consumed worldwide. Microencapsulated jabuticaba (Myrciaria cauliflora) extract ( $2 \%$ and $4 \% w / w)$ was added to fresh sausages [128] and the resulting product showed the same $(p>0.05)$ proximal composition, lower $(p<0.05)$ thiobarbituric acid reactive substances (TBARS) development (0.01-0.05 mg malonaldehyde, MDA/ kg sample, compared to 0.39-0.60 mg $\mathrm{MDA} / \mathrm{kg}$ ), and major color preservation compared to control and carmine-formulated sausages. Purified fucoxanthin from Tunisian seaweed (Cystoseira barbata) allowed reductions from 150 to $80 \mathrm{ppm}$ in the nitrite concentration of turkey-meat sausages due to 
enhanced color preservation and improved oxidative stability, but no antimicrobial evaluations were carried out, one of the main purposes of using nitrites [129]. Similar sausages were formulated with carotenoproteins from blue crab (Porturus segnis) shells (84.44\% yield, 1211-1135 $\mu \mathrm{g}$ GAE/g extract) [130], where the developed sausages exhibited a 10-day shelf life with decreasing diene formation, metmyoglobin, and heme iron preservation, and improved DPPH radical scavenging than control sausages.

The evaluation of colorants can also be used in cooked meat to preserve color and avoid lipid oxidation. Both complex processes still a major concern in loss of sensory quality, nutritional properties, and economic value [131]. Astaxanthins from Haematococcus pluvialis $(20 \mathrm{mg} / \mathrm{kg}, 40 \mathrm{mg} / \mathrm{kg}, 60 \mathrm{mg} / \mathrm{kg}$, and $80 \mathrm{mg} / \mathrm{kg}$ ) showed strong antioxidant properties when applied to fresh, frozen, and cooked lamb patties [75], showing $\mathrm{pH}$ preservation, lower TBARS levels than control patties (no antioxidants; and low $\mathrm{L}^{*}$, higher $a^{*}$, and higher $b^{*}$ values than control patties. More recently, Cunha et al. [132] reported the antioxidative properties of encapsulated pitaya (Hylocereus costaricensis) peel extract (100 and $1000 \mathrm{ppm}$ ) on pork patties subjected to high-pressure processing, manifested in slight $L^{*}$ and $b^{*}$ increases, $a^{*}$ preservation, color differences closer to 1 , preserved cohesiveness and springiness, and low concentrations of MDA along time.

As meat products are mainly associated with reddish and orange colors, carotenoids have especially found a niche in these food products. Moreover, since nitrites and nitrates are applied into these products to take advantage of the antibacterial properties, using nitrogen-based natural food-colorants could be an alternative to reduce the amount their amount, preventing health concerns associated to their use. Thus, betacyanins could be one of the most potential colorants to be used in these food systems, but process extraction and optimization is needed to test their curing ability, nitrosamine formation, and their ability to produce a desirable color.

\subsection{Other Food Products}

Natural colorants are widely used in pasta products to produce new ways of colored pasta, especially the popular "vegetable-added pasta". Dalla Costa et al. [133] used 20\% carrot (Daucus carota sbsp. sativus) flour as a substitute for $\beta$-carotene for commercial dry wheat (Triticum aestivum) pasta and found 307\% higher levels of carotenoids, $132 \%$ increased antioxidant capacity, and $608 \%$ higher total fiber compared to no carrot-added pasta. Saffron (Crocus sativus L.) enrichment $(0.2-0.4 \% w / w)$ of wheat flour pasta [134] decreased $\mathrm{L}^{*}$ but increased $\mathrm{a}^{*}$ and $\mathrm{b}^{*}$ values compared to commercial pasta, and no textural parameters were affected (hardness, cohesiveness, elasticity, and chewiness). In contrast, saffron allowed higher antioxidant capacity values (DPPH: 4-6 $\mu \mathrm{mol}$ Trolox equivalents/g dry base vs. $0.5-4 \mu \mathrm{mol}$ Trolox equivalents/g dry base in control pasta). Panelists positively scored saffron-added pasta in terms of aspect, color, aroma, taste, and global acceptability.

The addition of "Senduduk" fruit (Melastoma malabatrhicum L.) (2-10\%) to jackfruit jam enhanced $\beta$-carotene (300-314 g/100 mL), ANC (6.86-9.43 mg/L), TPC (0.99-1.34 mg/mL), and antioxidant capacity [135].

Cerezal Mezquita et al. [136] assayed lutein obtained from Muriellopsis sp. alga biomass as a natural and antioxidant in a mayonnaise-like dressing sauce. Prepared mayonnaises showed high pigment stability in the matrix based on the $\mathrm{L}^{*}, \mathrm{a}^{*}$, and $\mathrm{b}^{*}$ values. The tested mayonnaise showed similar moisture and lipids than corn oil mayonnaise and higher lutein than commercially available mayonnaises.

Finally, the plenty applications of natural food-colorants demonstrate their potential to be incorporated in several food systems beyond the traditional formulations. New sources are constantly being incorporated as sources of colorants after an optimization procedure to overcome not only technological aspects, but also legal and toxicological concerns, and the consumers' attitudes towards these colorants. A summary of all technological applications of natural colorants in food systems is shown in Table 2. 
Table 2. Technological applications of natural colorants in food systems.

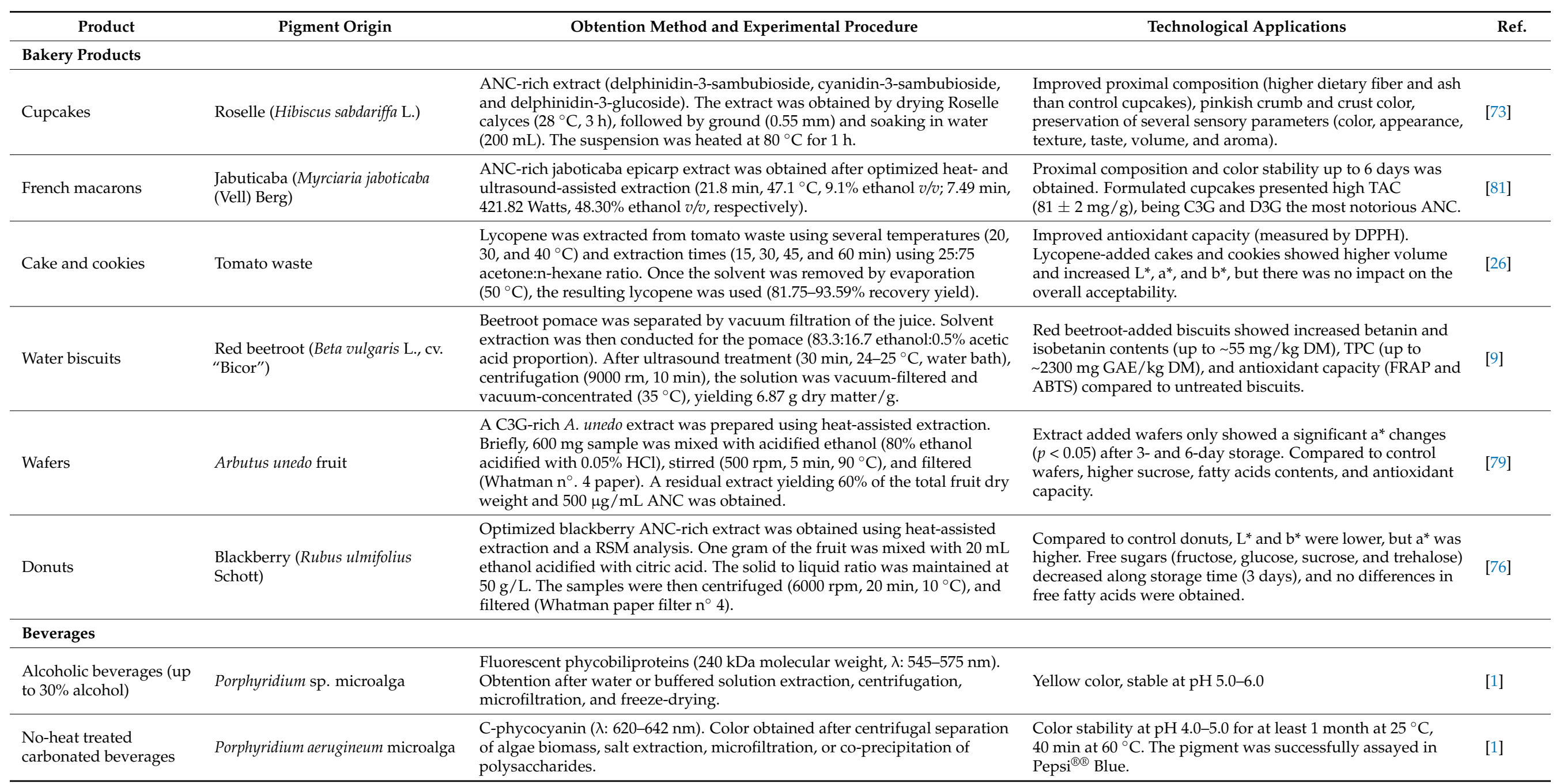


Table 2. Cont

\begin{tabular}{|c|c|c|c|c|}
\hline Product & Pigment Origin & Obtention Method and Experimental Procedure & Technological Applications & Ref. \\
\hline $\begin{array}{l}\text { Green tea model } \\
\text { beverage }\end{array}$ & Purple carrot & $\begin{array}{l}\text { ANC solution }(0.05 \%) \text { with } 20 \mathrm{mM} \text { calcium hydroxide until reaching } 0.02 \% \text {, } \\
\text { prepared at pH: } 3.0\end{array}$ & $\begin{array}{l}\text { Improvement of color stability from ANC ( } 2.62-6.73 \text { days }) \text {, } \\
\text { even better at higher temperatures }\left(25-40^{\circ} \mathrm{C}\right) \text {. }\end{array}$ & [13] \\
\hline Sports beverage & $\begin{array}{l}\text { Black bean (Phaseolus vulgaris L.) } \\
\text { seed coat }\end{array}$ & $\begin{array}{l}\text { Seed coats were subjected to an aqueous extraction }\left(40^{\circ} \mathrm{C}, 4 \mathrm{~h}\right) \text {, } \mathrm{pH} \text {-adjusted } \\
\text { with citric acid ( } 2.0) \text {, centrifuged }(27,200 \times g, 15 \mathrm{~min}) \text {, filtered, and stored at } \\
-20^{\circ} \mathrm{C} \text { (ANC-rich extracts). For their addition to a commercial sports } \\
\text { beverage, extracts }(0.1 \mathrm{mg} / \mathrm{mL} \text { or } 0.26 \mathrm{mg} / \mathrm{mL}) \text { were added to } 250 \mathrm{~mL} \text { of a } \\
\text { commercial glacier cherry-flavored sports drink. } \beta \text {-Cyclodextrin was then } \\
\text { added to reach } 2 \mathrm{~g} / 100 \mathrm{~mL} \text { concentration. }\end{array}$ & $\begin{array}{l}\text { ANC extract-added beverages co-pigmented with } \\
\beta \text {-cyclodextrin exhibited longer half-life, similar lightness, } \\
\text { lower } \mathrm{a}^{*} \text {, and higher } \mathrm{b}^{*} \text { than commercial sports beverages. }\end{array}$ & [87] \\
\hline \multirow{5}{*}{$\begin{array}{l}\text { Model commercial } \\
\text { beverages }\end{array}$} & Pitaya (Stenocereus pruinosus). & $\begin{array}{l}\text { Pitaya was collected, homogenized }(1 \mathrm{~g}) \text {, mixed with } 4 \mathrm{~mL} \text { water, vortexed } \\
(3150 \mathrm{rpm}, 1 \mathrm{~min}) \text {, and centrifuged }(10,576 \times g, 20 \mathrm{~min}) \text {, and supernatants } \\
\text { were recovered. }\end{array}$ & $\begin{array}{l}\text { Yellow beverages displayed several yellow-orange shades. } \\
\text { Juice-addition (5\%) showed similarity with commercial } \\
\text { beverages, retaining up to } 75 \% \text { of total betaxanthins. }\end{array}$ & [34] \\
\hline & $\begin{array}{l}\text { Yellow bell pepper } \\
\text { (Capsicum annuum L.) }\end{array}$ & $\begin{array}{l}\text { Ripe yellow bell peppers were dried }\left(55^{\circ} \mathrm{C}, 15 \mathrm{~h}\right) \text {, powdered, and pigments } \\
\text { were extracted after alcohol maceration with ethyl alcohol and water }(90: 10 \\
v / v) \text {. Hexane partition was carried out, and the organic solvent was } \\
\text { evaporated }\left(40^{\circ} \mathrm{C} \text {, vacuum rotary evaporator). Inclusion complexes with }\right. \\
\beta \text {-cyclodextrin were prepared }(1: 2,1: 4 \text {, and } 1: 6 \mathrm{w} / \mathrm{w}) \text { using ultrasound-freeze } \\
\text { drying and molecular inclusion. }\end{array}$ & $\begin{array}{l}L^{*} \text { and } a^{*} \text { parameters increased together with extract } \\
\text { concentration, but } b^{*} \text { decreased in the tested beverage models. }\end{array}$ & [88] \\
\hline & $\begin{array}{l}\text { Yellow-orange cactus } \\
\text { (Opuntia ficus-indica) }\end{array}$ & $\begin{array}{l}\text { Cactus pulp was vacuum-concentrated }\left(30^{\circ} \mathrm{C}, 17 \mathrm{mbar}\right) \text { up to } 45^{\circ} \mathrm{Brix} \text {. For } \\
\text { the freeze-dried extract, maltodextrin was added }(1: 1 \text { pulp:maltodextrin), } \\
\text { homogenized, frozen }\left(-50^{\circ} \mathrm{C}, 48 \mathrm{~h}\right) \text {, and dried }\left(-55^{\circ} \mathrm{C}, 0-0.133 \mathrm{mbar}\right) \text {. }\end{array}$ & $\begin{array}{l}\text { Betaxanthin-rich extracts contained } 256.53-264.76 \mathrm{mg} \\
\text { indicaxanthin equivalents } / \mathrm{kg} \text {. Soft-drink beverages } \\
\text { displayed significant color changes after a } \\
5 \text { days-storage }\left(4^{\circ} \mathrm{C}\right) \text {. }\end{array}$ & [89] \\
\hline & $\begin{array}{l}\text { Annato from Bixa orellana L. seeds, } \\
\text { gardenia yellow from Gardenia } \\
\text { jasminoides Ellis, lutein from } \\
\text { marigold flowers or Tagetes erecta } \\
\text { L., curcumin from turmeric or } \\
\text { Curcuma longa L., and safflower } \\
\text { extract from Carthamus tinctorius L. }\end{array}$ & $\begin{array}{l}\text { All colorants were acquired locally from commercial manufacturers. } \\
\text { Beverages were formulated with Mcllvaine buffer }(\mathrm{pH}: 3.5,5.5 \text {, and } 7.5 \text {; } \\
\text { concentration: } 0.001 \%, 0.005 \%, 0.01 \%, 0.02 \%, 0.03 \%, 0.05 \%, 0.10 \% \text {, and } \\
0.30 \%) \text { with and without ethanol }(15 \% \mathrm{v} / \mathrm{v}) \text {. }\end{array}$ & $\begin{array}{l}\text { Gardenia, safflower, and curcumin displayed the highest } \\
\text { color intensities and lowest turbidity levels. Safflower } \\
\text { colorant was the most heat- }\left(25-80^{\circ} \mathrm{C}\right) \text { and light-stable } \\
\left(550 \text { Watts } / \mathrm{m}^{2}, 30^{\circ} \mathrm{C}\right) \text {. }\end{array}$ & [91] \\
\hline & Purple corn (Zea mays L.) pericarp & $\begin{array}{l}\text { ANC and flavones were extracted in a 1:2 ratio }(w / v) \text { from the corn seeds } \\
\text { after aqueous incubation }\left(80^{\circ} \mathrm{C}, 1 \mathrm{~h}\right) \text { under constant shaking. After cooling, } \\
\text { extracts were filtered (Whatman } \mathrm{n}^{\circ} 1 \text { paper) and stored frozen at }-80^{\circ} \mathrm{C} \text {. }\end{array}$ & $\begin{array}{l}\text { Flavone addition increased the average half-life of cyanidin or } \\
\text { pelargonidin-rich model beverages, but cyanidin beverages } \\
\text { were the most stable ones. }\end{array}$ & [92] \\
\hline Protein beverage & Jabuticaba (Plinia cauliflora) & $\begin{array}{l}\text { Jabuticaba skins }(40 \mathrm{~g}) \text { were ground, mixed with } 70 \% v / v \text { acidified ethanol } \\
\text { with citric acid }(\mathrm{pH}: 2.0) \text {, and left to stand for } 24 \mathrm{~h}\left(5^{\circ} \mathrm{C}\right) \text {. The extract was } \\
\left.\text { vacuum-filtered (Whatman } \mathrm{n}^{\circ} 1\right) \text { and concentrated in a vacuum rotary } \\
\text { evaporator }\left(40^{\circ} \mathrm{C}\right) \text {. The extract was added to whey }(0.5 \%, 2.0 \%, 4.0 \% \text {, and } \\
\left.6.0^{\circ}\right) \text {-based beverages, formulated with mineral water, sugar }(15 \% \mathrm{w} / \mathrm{v}) \text {, } \\
\text { strawberry pulp }(10 \% \mathrm{w} / \mathrm{v}) \text {, gum arabic }(0.45 \% \mathrm{w} / \mathrm{v}) \text {, potassium sorbate } \\
(0.03 \% w / v) \text {, and citric acid. }\end{array}$ & $\begin{array}{l}\text { D3G and C3G were the main ANC from the extract. } \\
\text { Formulated beverages showed whey } \\
\text { concentration-dependent TPC ( } 32.6-83.6 \mathrm{mg} \mathrm{GAE} / 100 \mathrm{~g}) \text { and } \\
\text { antioxidant capacity }(1.2-1.8 \mu \mathrm{M} \text { TEAC/g) values }\end{array}$ & [93] \\
\hline
\end{tabular}


Table 2. Cont.

Product

Pigment Origin

Purple sweet potato (Ipomoe batatas L.) cv. Ayamurasaki

\section{Obtention Method and Experimental Procedure}

ANC were extracted from purple sweet potato and encapsulated with $6 \%$

/v maltodextrin. The jelly drinks contained $0.3 \% v / v$ jelly pow with $6 \%$

$0 / v$ sucrose dissolved $75^{\circ} \mathrm{C}$ for 5 min. Potassium citrte and sodium benzoate were added, and the product was cooled at $40^{\circ} \mathrm{C}$.

\section{Technological Applications}

Jelly drink

Pitaya was collected, homogenized $(1 \mathrm{~g})$, mixed with $4 \mathrm{~mL}$ water, vortexed (3150 rpm, $1 \mathrm{~min})$, and centrifuged $(10,576 \times g, 20 \mathrm{~min})$, and supernatants were recovered.

Betalains-rich extracts were obtained by crushing cactus fruit pulp and removing seeds by filtration. The product was then freeze-dried (1.9-2.3 g/100 g final moisture), and macerated with phosphate buffer (pH 5.5, 1:2 pulp:buffer ratio). The betalain-rich extract was mixed with sodium alginate ( $15 \mathrm{~g} / \mathrm{L}, \mathrm{pH}: 5.5)$, slowly added to calcium chloride solution $(0.015 \mathrm{M})$ for $1 \mathrm{~min}$, and washed with distilled water. The obtained beads were then dehydrated $\left(30^{\circ} \mathrm{C}, 24 \mathrm{~h}\right.$, forced-air circulating oven)

Peel from F. carica and epicarp from P. spinosa were freeze-dried and milled (20 mesh size). Ultrasound-assisted extraction was conducted: $100 \mathrm{~mL}$ acidified ethanol (figs: $180 \mathrm{~g} / \mathrm{L}, 21 \mathrm{~min}, 310 \mathrm{~W}$ ) or 50:50 ethanol:water (blackthorns: $75 \mathrm{~g} / \mathrm{L}, 5 \mathrm{~min}, 400 \mathrm{~W}$ ). Samples were then centrifuged $\left(6000 \mathrm{rpm}, 20 \mathrm{~min}, 10^{\circ} \mathrm{C}\right)$, filtered (Whatman $\left.\mathrm{n}^{\circ} 4\right)$, and supernatants were freeze-dried. Cyanidin-3-rutinoside-rich fig and cyanidin-3-rutinoside/ peonidin-3-rutinoside-rich blackthorn extracts were obtained.

Fig (Ficus carica) and blackthorn (Prunus spinosa L.)

Saffron $(1 \mathrm{~g})$ was extracted with water under constant shaking in a water bath $\left(25^{\circ} \mathrm{C}, 60 \mathrm{~min}, 30 \mathrm{kHz}\right)$. Beetroots were washed, peeled, and extracted with water using a commercial juice extractor. Both extracts were with water using a commercial juice extractor. Both extracts were
microencapsulated using blends of gum arabic, modified starch, and chitosan, and mixtures were encapsulated by freeze-drying $(0.017 \mathrm{mbar}$ chitosan, and mix
$-57^{\circ} \mathrm{C}$, and $48 \mathrm{~h}$ )

Frozen Açaí pulp was thawed $\left(25^{\circ} \mathrm{C}\right)$, maltodextrin was added $(60 \mathrm{~g} / 100 \mathrm{~g})$ Frozen Açai pulp was thawed $\left(25^{\circ} \mathrm{C}\right)$, maltodextrin was added $(60 \mathrm{~g} / 100$
and the mixture was homogenized $(200 \mathrm{~L} / \mathrm{h}, 10 \mathrm{HP})$. The powder was and the mixture was homogenized $(200 \mathrm{~L} / \mathrm{h}, 10 \mathrm{HP})$. The powder was
obtained by spray-drying $(0.5 \mathrm{~mm}$ diameter nozzle and $6000 \mathrm{rpm}$ atomize obtained by spray-drying (0.5 mm diameter nozzle and $6000 \mathrm{rpm}$ atomizer, IAT: $170{ }^{\circ} \mathrm{C}$, OAT: $80^{\circ} \mathrm{C}$, flow rate: $10-15 \mathrm{~kg} / \mathrm{h}$ ). This pow
candies prepared in an atmospheric batch system cooker.

The Uvaia by-product (peels and seeds) was thawed, centrifuged, and oven-dried $\left(40^{\circ} \mathrm{C}, 24 \mathrm{~h}\right)$. Seeds were removed, and peels were milled (particle size: $37 \mu \mathrm{m}$ ). The powder was added to hard-panning confection made after cooking gummy candies $\left(110^{\circ} \mathrm{C}\right)$, adding starch, and following sealing and panning stages.
Beverages stored at $5{ }^{\circ} \mathrm{C}$ without light exposure presented the lowest $\mathrm{ANC}$ and $\mathrm{b}^{*}$ decrease, and average shelf-life of 200 days. 
Table 2. Cont.

Product Pigment Origin

Jelly gummy candies

Black Elderberry (Sambucus nigra)

Nannochloropsis oculata microalga

Transparent lollipops

made from sugar

solutions

Dry sugar-drop candie

for cake decoration

Porphyridium sp. microalga

\section{Milk, dairy, and dairy-like products}

Ayrampo (Opuntia soehrensii Britton and Rose) seed

Yogurt

\section{Obtention Method and Experimental Procedure}

nigra dyes obtained from fruits, flowers, and their mixture were freeze-dried (100 g of raw material mixed with $200 \mathrm{~mL}$ water, boiled for $10 \mathrm{~min}$, frozen at $-60^{\circ} \mathrm{C}$, and lyophilized). The obtained powder was dehydrated ( $48 \mathrm{~h}$ in heating shelves at $30^{\circ} \mathrm{C}, 0.5$ bar pressure). Jellies made from gelatin, Agar, and honey were used to add the powdered dyes.

Method 1: Algal biomass was dried in a spray-dryer $(6 \mathrm{bar}, 1.40 \mathrm{~mL} / \mathrm{min}$ flow, and 65 mbar atomization pressure). IAT: $180{ }^{\circ} \mathrm{C}$, OAT: $95{ }^{\circ} \mathrm{C}$. 1:1.

Method 2: Alga:maltodextrin proportion was mixed (10,000 rpm, $10 \mathrm{~min})$.

Encapsulation was carried out in a freeze-dryer.

For adding the encapsulated products to white chocolate $\left(6 \mathrm{~h}, 60^{\circ} \mathrm{C}\right.$ conching time), alga powders $(0.125,0.25,0.50$, and $0.75 \mathrm{~g} / 100 \mathrm{~g})$ were added on the last $15 \mathrm{~min}$ of the conching process.

Fluorescent phycobiliproteins ( $240 \mathrm{kDa}$ molecular weight, $\lambda: 545-575 \mathrm{~nm}$ ). Obtention after water or buffered solution extraction, centrifugation, microfiltration, and freeze-drying.

\section{Technological Applications}

Ref.

Extract-added jelly gummy candies contained ANC such as cyanidin.3-O-sambubioside-5-glucoside,

cyanidin-3,5-diglucoside, cyanidin-3-O-sambubioside, and cyanidin-3-O-rutinoside, and high antioxidant level measured by FRAP and DPPH.

The resulting alga-added chocolate exhibited higher $\mathrm{a}^{*}$ and hue values than the control white chocolate samples.

Chlorophyll $a$ values ranged from 9.60 to $27.2 \mu \mathrm{g} / \mathrm{g}$. No significant differences $(p<0.05)$ were shown for the sensory analysis of appearance, texture, and smell, despite being evaluated with lower values than the control chocolate samples.

Pinkish-red color on confections, stable at $60^{\circ} \mathrm{C}$ for $30 \mathrm{~min}$ and long shelf-life (6 months) at $\mathrm{pH} 6.0-7.0$
Betalains were obtained by soaking the seeds in distilled water ( $\mathrm{pH}: 4.5$, Betalains were obtained by soaking the seeds in distilled water ( $\mathrm{pH}: 4.5$,
acidified with $0.25 \mathrm{~N} \mathrm{HCl}, 1: 3 \mathrm{w} / \mathrm{v}$ ) for $24 \mathrm{~h}$ at $30^{\circ} \mathrm{C}$. Samples were then acidified with $0.25 \mathrm{~N} \mathrm{HCl}, 1: 3 \mathrm{w} / \mathrm{v}$ ) for $24 \mathrm{~h}$ at $30^{\circ} \mathrm{C}$. Samples were then
centrifuged ( $4000 \mathrm{rpm}$ for $15 \mathrm{~min})$, and supernatants were collected and filtered (Whatman paper $n^{\circ} 4$ ). The purification was carried out by gel filtration chromatography (Bio-Gel P-2 columns) using a freeze-dried liquid-liquid extract with ethyl acetate (4:1 solvent:betalain extract) at pH: $4.5(12 \mathrm{~h})$. The fractions were eluted with distilled water $(6.8 \mathrm{~mL} / \mathrm{h})$.Betacyanins were extracted by mixing the seeds' extract with Mcllvaine buffer (0.15 M, pH: 5.6) until obtention of absorbance between 0.2 and $0.8(537 \mathrm{~nm})$.

Commercially acquired curcumin $(10 \mathrm{mg})$ was mixed with Tween $80(10 \mathrm{mg})$ and stirred for $5 \mathrm{~min}$. After sonication (15 $\mathrm{min})$ under pulse conditions ( $30 \mathrm{~s}$, $\left.120 \mathrm{~W}, 25^{\circ} \mathrm{C}\right)$, the solvent was evaporated $\left(40^{\circ} \mathrm{C}, 24 \mathrm{~h}\right)$, and the solid was

Curcumin (Curcuma longa)

Petals of Dahlia mignon, rose from Rosa damascena "Alexandria" an Rosa gallica "Francesca"; and flowers from Centaurea cyanus $\mathrm{L}$ ground with pistil and mortar $(8.30 \% w / w$ curcumin was obtained).

Different proportions of natural curcumin and encapsulated curcumin were added to commercial natural yogurts.

Flowers were reduced to powder (20 mesh), and $1 \mathrm{~g}$ of the dry material was mixed with $50 \mathrm{~mL}$ of distilled water to be extracted by maceration $\left(25^{\circ} \mathrm{C}\right.$, $150 \mathrm{rpm}, 1 \mathrm{~h}$ ). Mixtures were filtered with Whatman Paper n 4, frozen, and freeze-dried. Commercial yogurts ( $3.8 \%$ fat) were supplemented with Dahli $(0.05 \% \mathrm{v} / \mathrm{v})$, rose $(0.15 \% \mathrm{v} / \mathrm{v})$, or Centaurea $(0.10 \% \mathrm{v} / \mathrm{v})$ extracts.
Betacyanin-added yogurts showed lower $\mathrm{L}^{*}$ and higher $\Delta \mathrm{E}$ than control yogurts, but the 5-week storage showed similar performance than the synthetic colorant Red no. 40 in color retention $(>94 \%)$ and $\mathrm{L}^{*}$ values.

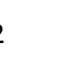

(5)

Formulated yogurts showed color ranges closer to orange (mango, peach, or papaya-like color). During 7-day storage, $a^{*}$ and $b^{*}$ values decreased compared to control yogurts, but the overall color was maintained a long time.

Manufactured yogurts exhibited the same proximal composition and color parameters as artificially-colored yogurts (E163) but showed a higher monounsaturated fatty acids composition (oleic acid). 
Table 2. Cont.

Product

Pigment Origin

Jabuticaba (Myrciaria jaboticaba

(Vell) O. Berg) and jamelão

(Syzygium cumini (L.) Skeels)

Strawberry (Fragaria ananassa)

Red beetroot (Beta vulgaris L.),

opuntia

(Raphanus sativus L.)
Fermented flavored

milk

Canthaxanthin from Dietzia natronolimnaea HS-1

\section{Obtention Method and Experimental Procedure} dried $\left(60^{\circ} \mathrm{C}\right.$, air speed: $\left.1 \mathrm{~m} / \mathrm{s}, 22 \mathrm{~h}\right)$. The dried product was ground and used to formulate yogurts $(0.3$ and $0.5 \% v / v)$.
Fruits were washed, and peels were manually separated from the pulp,

ANC from Strawberries were extracted after mixing strawberry $(0.5-2.0 \mathrm{~g})$ with $85 \%$ distilled water and $15 \% \mathrm{HCl}(0.1 \mathrm{M})(\mathrm{pH}: 1.3)$ under agitation (400-800 rpm, 1-15 $\mathrm{min})$, followed by centrifugation $(2486 \times g)$, and filtration $(13 \mu \mathrm{m})$.

Betalains-rich extracts (red beetroot and opuntia) were prepared using small hand-peeled raw materials pieces $(5 \mathrm{~g})$ and adding a water:ethanol:acetic acid $(66.6: 33: 0.33 \mathrm{v} / \mathrm{v} / \mathrm{v})$ solution $\left(25^{\circ} \mathrm{C}\right)$ for $48 \mathrm{~h}$ (beetroot) or $20 \mathrm{~min}$ (opuntia). Mixtures were filtered and centrifugated (500 rpm, $16 \mathrm{~min}$ ), and solvents were evaporated by rotary evaporation $\left(40^{\circ} \mathrm{C}\right)$.

The ANC-rich extract (Roselle) $5 \mathrm{~g}$ of flowers were mixed with a The ANC-rich extract (Roselle) $5 \mathrm{~g}$ of flowers were mixed with a
water:ethanol:acetic acid $(70: 29.7: 0.3 \mathrm{v} / \mathrm{v} / \mathrm{v})$ solution $\left(4^{\circ} \mathrm{C}, 72 \mathrm{~h}\right)$. The mixture was filtered, and the solvent was evaporated $\left(40^{\circ} \mathrm{C}\right.$, rotary evaporator). ANC-rich extract from red radish was obtained by making blends of radis $(25 \mathrm{~g})$ with water/acetic acid $(95: 5 \mathrm{v} / \mathrm{v})(100 \mathrm{~mL})$, and the solution was kep at $4{ }^{\circ} \mathrm{C}$ for $18 \mathrm{~h}$. After filtration, the solvent was evaporated. All extracts were freezedried $\left(-80^{\circ} \mathrm{C}, 5\right.$ days), nanoencapsulated in liposomes, and applied to soy-based yogurt alternative.

D. natronolimnaea HS-1 was transferred to a $100 \mathrm{~mL}$ liquid-pre-culture medium $(10 \mathrm{~g} / \mathrm{L}$ glucose, $5 \mathrm{~g} / \mathrm{L}$ peptone, $5 \mathrm{~g} / \mathrm{L}$ yeast extract, and $3 \mathrm{~g} / \mathrm{L}$ malt extract). Then, the inoculum was transferred to another medium $(10 \mathrm{~g} / \mathrm{L}$ yeast and $40 \mathrm{~g} / \mathrm{L}$ beetroot molasses) and incubated $\left(28^{\circ} \mathrm{C}, 180 \mathrm{rpm}\right.$ for 5 days). The biomass was removed by centrifugation $(8000 \times g, 5 \mathrm{~min})$, washed with physiological serum $(9 \% \mathrm{NaCl})$, and extracted with ethanol by centrifugation $(8000 \times g, 10 \mathrm{~min})$. The pigment was microencapsulated using oil/water/oil multiple emulsion external gelation. Capsules were applied to pasteurized or flavored fermented milk samples $(15 \mathrm{mg} / \mathrm{L})$.

Grapes' husks were manually separated and stored at $-18^{\circ} \mathrm{C}$. Then, $25 \mathrm{~mL}$ of acetate buffer (pH: 4.0) was added to $5 \mathrm{~g}$ of frozen husks, heated at $40^{\circ} \mathrm{C}$ and stirred $(150 \mathrm{rpm}, 30 \mathrm{~min})$. The resulting extracts were freeze-dried ( -55 to $57^{\circ} \mathrm{C}, 200 \mu \mathrm{Hg}, 4$ days) to obtain ANC-concentrated extracts. Extracts were added to the prepared fermented product from kefir $(400 \mathrm{~mL}$ ANC extract + 2 L kefir).
Colorant-added yogurts retained less than $50 \%$ of antioxidant capacity after 21-day storage. No differences in $\Delta \mathrm{E}$ were hown between the formulations and a reference yogurt.

Jabuticaba-colored yogurts displayed better appearance, flavor, and color scores than jamelão-colored yogurts $(p<0.05)$ To differences were found for the appearance between not-colored and jabuticaba-formulated yogurts.

ANC-addition produced yogurts with $10-40 \mathrm{mg} / 100 \mathrm{~g}$ TAC and a remaining red color at $\mathrm{pH}: 4.6$ (yogurts' $\mathrm{pH}$ ) and $4^{\circ} \mathrm{C}$ storage.

Yogurts contained betacyanins, ANC, or betalains accordingly the origin of their extracts. High color retention was observed after 21 days of storage, but Roselle and red radish-origin colorants were the most stable.

$\mathrm{pH}, \mathrm{L}^{*}$, and $\mathrm{a}^{*}$ decreased during 16-day storage, compared to initial values. High ANC retentions were obtained at the same time (77-88\%). ANC-added kefir exhibited similar physical properties as natural kefir

(1)


Table 2. Cont.

Fresh Roselle calyces were washed and dried $\left(50^{\circ} \mathrm{C}, 36 \mathrm{~h}\right)$ in a hot-air ove dryer, powdered ( $0.8 \mathrm{~mm}$ particle size), and mixed with proper amounts of deionized water to achieve $5 \%, 10 \%, 15 \%$, and $20 \% v / v$. Mixtures were soaked in a water bath $\left(75^{\circ} \mathrm{C}, 1 \mathrm{~h}\right.$ ), filtered (Whatman paper $\mathrm{n}^{\circ} 1$ ), and residues were extracted with $300 \mathrm{~mL}$ water as described.

Microalga was cultured in $\mathrm{F} / 2$ culture media prepared with seawater ( $350 \mathrm{~g} / \mathrm{L}$ salinity, $\mathrm{pH}: 7.5,25^{\circ} \mathrm{C}, 2 \% \mathrm{CO}_{2}$ ), and biomasses were harvested, concentrated, and dried in a spray-dryer $\left(1.0 \mathrm{~m}\right.$ nozzle diameter, AIT: $70^{\circ} \mathrm{C}$ Microalga (Nannochloropsis oculata Diacronema vilkianum)

OAT: $95^{\circ} \mathrm{C}, 7-9 \mathrm{~mL} / \mathrm{min}$ feed rate, residence chamber: $1.5 \mathrm{~s}$ ). The spray-dried product was mixed with ice cream mix $(0.1,0.2$, and $0.3 \mathrm{~g} / 100 \mathrm{~g}$ ice cream) by centrifugation (1300 rpm, $3 \mathrm{~min}$ ), followed by rapid colling a $4{ }^{\circ} \mathrm{C}$. Samples were aged $24 \mathrm{~h}$ at $4{ }^{\circ} \mathrm{C}$, whipped $\left(0^{\circ} \mathrm{C}, 10 \mathrm{~min}\right)$, and frozen at $-18^{\circ} \mathrm{C}$ for $24 \mathrm{~h}$

Betacyanins were extracted from the pulp using distilled water, $50 \%$ ethano or $95 \%$ ethanol in a 1:1 or 1:2 fresh weight:solvent ratio $(w / v)$. Pectinase $(0$ $0.5 \%, 1.0 \%, 1.5 \%, 2.0 \%$, or $2.5 \%$ ) was used to degrade the pectin. The pulp

Red pitahaya (Hylocereus polyrhizus) was then homogenized ( $2 \mathrm{~h}, 15,000 \times g, 15 \mathrm{~min})$, and supernatants were placed on a vacuum oven for $24 \mathrm{~h}$.

placed $150 \mathrm{mg} / \mathrm{mL})$ were added to fresh cow milk and pasteurized $\left(63^{\circ} \mathrm{C}\right.$ $30 \mathrm{~min})$. After cooling $\left(4^{\circ} \mathrm{C}\right)$, a commercial powdered ice cream pre-mix $(2 \%$ fat) was used, and the mixture was placed in an ice-cream maker. The fat) was used, and the mixture was placed
resulting ice cream was frozen at $-18^{\circ} \mathrm{C}$.

Saffron flowers $(0.5 \mathrm{~g})$ were ground and added to $0.5 \mathrm{~L}$ of milk $(1000 \mathrm{mg} / \mathrm{L})$ at $42{ }^{\circ} \mathrm{C}$ under slow agitation for $45 \mathrm{~min}$. The mixture was filtered $(500 \mu \mathrm{m}$ mesh) and used in the cheese trials. For the cheese, ovine milk $(8 \mathrm{~L})$ was pasteurized $\left(68^{\circ} \mathrm{C}, 10 \mathrm{~min}\right)$, the milk was cooled $\left(30^{\circ} \mathrm{C}\right)$, and inoculated

Cheese Porphyridium cruentum, and pasteurized $\left(68^{\circ} \mathrm{C}, 10 \mathrm{~min}\right)$, the milk was cooled $\left(30^{\circ} \mathrm{C}\right)$, and inoculated
with a starter culture $\left(10^{8} \mathrm{cfu} / \mathrm{mL}\right.$ at $1 \%$ rate: $\left.3.50 \times 10^{6} \mathrm{cfu} / \mathrm{mL}\right)$. Saffron with a starter culture $\left(10^{8} \mathrm{cfu} / \mathrm{mL}\right.$ at $1 \%$ rate: $\left.3.50 \times 10^{6} \mathrm{cfu} / \mathrm{mL}\right)$. Saffron extract (100,150, and $200 \mathrm{~mL}$ of the extract), commercial rennet, and salt were added. Mixtures were incubated $\left(25-28^{\circ} \mathrm{C}, 12 \mathrm{~h}\right)$, mixtures

Saffron (Crocus sativus L)

Cylindrical fruits with a sweet-sour taste were powdered (particle size: $85 \mu \mathrm{m})$, mixed with deodorized refined sunflower oil (1 g extracted with $12 \mathrm{~mL}$ of oil), stirred, and sonicated at two different temperatures $\left(20^{\circ} \mathrm{C}\right.$ an

Sea buckthorn (Hippophae rhamnoides L.) cv. "Elizaveta" $\left.45^{\circ} \mathrm{C}\right)$ and three extraction times $(0.5 \mathrm{~h}, 1.0 \mathrm{~h}$, and $1.5 \mathrm{~h})$. The extracts were centrifuged (7000 rpm, $10 \mathrm{~min}$ ), decanted, and stored at $4{ }^{\circ} \mathrm{C}$ in dark glass bottles. The extracts ( $22 \%$ of cheese's mass) were added to manufactured cream cheeses at $20^{\circ} \mathrm{C}$, homogenizing the samples for $5-10 \mathrm{~min}$.

fruits
$5 \%$ Roselle-added ice creams displayed the best viscosity $(242.3 \mathrm{cP})$, melting rates $(1.3 \mathrm{~g} / \mathrm{min})$, and color attributes ( ${ }^{*}: 72$ ) among the formulations. Moreover, the lowest Roselle-added ( $5 \%$ and $10 \%$ ) ice creams displayed no differences $(p<0.05)$ in the sweetness and gummy taste compared to commercial vanilla-flavored ice cream.

Formulated ice creams exhibited lower apparent viscosity and lower performance of melting behavior compared to control ice creams. P. cruentum provided a pinkish color, while the other two microalgae exhibited a greenish color. TPC were higher $(p<0.05)$ than the control ice creams, particularly for $\mathrm{N}$. oculata alga (up to $225 \mathrm{mg} \mathrm{GAE} / \mathrm{kg}$ ice cream). No differences were shown between the $P$. cruentum-added ice creams and color, texture, taste, odor, all acceptability.

The betacyanin concentration and free radical scavenging activity increased during 21 -day storage in the su ice creams. No sensory evaluations were conducted.
The saffron addition did not affect moisture, total protein, salt, and fats, but these cheese showed the lowest $\mathrm{pH}$ (4.13-4.36) and the highest antioxidant capacity values (up to $25.97 \%$ RSA). Cheese with the lowest saffron concentration $(50 \mathrm{mg} / \mathrm{L}$ ) received the same sensory score as control cheeses.

Manufactured cheeses incorporated chlorophylls, carotenoids, and TPC from the fruits' extracts and received better sensory scores than tartrazine-supplemented cheeses. 
Table 2. Cont.

Product Pigment Origin

Meat and meat products
Jabuticaba (Myrciaria cauliflora)

Sausages
Brown seaweed (Cystoseira barbata)

Extra 300 residue:water) under mechanical agitation $(6 \mathrm{~h})$. The fluid was filtered and concentrated to $1 / 3$ of its original volume (rotary evaporation: $60^{\circ} \mathrm{C}$ under vacuum). The extract was mixed with maltodextrin, stirred, and microencapsulated in a spray dryer (atomizing nozzle diameter: $1.5 \mathrm{~mm}$, IAT: $150^{\circ} \mathrm{C}, 40 \mathrm{~L} / \mathrm{min}$ aiflow, and $30 \mathrm{~mL} / \mathrm{min}$ feed rate). Extracts $(2 \%$, IAT. $150{ }^{\circ} \mathrm{C}, 40 \mathrm{~L} / \mathrm{min}$ airflow, and $30 \mathrm{~mL} / \mathrm{min}$ feed rate). Extracts ( $2 \%$ and $\mathrm{NaCl}$, condiments, and $\mathrm{Na}_{5} \mathrm{P}_{3} \mathrm{O}_{10}$ ).

Brown seaweed was collected, water with seawater and tap water $\left(25^{\circ} \mathrm{C}\right)$ at $4{ }^{\circ} \mathrm{C}$. Fucoxanthins were extracted by mixing the algal powder $(100 \mathrm{~g})$ with acetone:methanol $\left(7: 3 \mathrm{v} / \mathrm{v}, 24 \mathrm{~h}, 30^{\circ} \mathrm{C}\right)$ under stirring $(250 \mathrm{rpm})$.

Extracts were concentrated and redissolved in $100 \mathrm{~mL}$ methanol, mixed with $300 \mathrm{~mL}$ water and $400 \mathrm{~mL}$ diethyl ether. The upper phase containing the pigment was collected, dried in a rotary evaporator, and dissolved in $5 \mathrm{~mL}$ the pigment.

Blue crabs were obtained in fresh conditions. Shells were removed, washed, stored at $-20^{\circ} \mathrm{C}$, macerated with solvent preparation (50:50

Blue crabs (Portunus segnis) hexane:isopropanol) in a 30:1 solvent:raw material proportion under constant stirring ( $100 \mathrm{rpm}, 120 \mathrm{~h})$. Residual solvent was evaporated, and carotenoproteins were obtained with a petroleum ether:acetone:water $(15: 75: 10 \mathrm{v} / \mathrm{v} / \mathrm{v})$ mixture $\left(4^{\circ} \mathrm{C}, 24 \mathrm{~h}\right)$.
Residues from Jabuticaba fruit (peels and seeds) were mixed with water (1:3 dried (20 days), milled ( $0.2 \mathrm{~mm}$ mesh size), and stored in amber glass bottles

No differences in the moisture, protein, lipids, or fat $(p>0.05)$ were found between all formulations. Jabuticaba-formulated sausages exhibited low TBARS formation $(0.01-0.05 \mathrm{mg}$ MDA/kg sample), $\mathrm{L}^{*}$ (57.5-63.4), $\mathrm{a}^{*}(5.7-9.1)$, and b* (4.8-11) changes during 15-days storage, compared to control sausages. Only $2 \% v / v$ manufactured sausage showed the same overall acceptance as control and carmine-added sausages.

Fucoxanthins-added sausages showed less $\mathrm{L}^{*}$, but higher a and $b^{*}$ values than control sausages. The reddish color was improved compared to $150 \mathrm{ppm}$ sodium nitrite and vitamin C references. Sausages containing fucoxanthin exhibited less TBARS formation compared to $80 \mathrm{ppm}$ sodium nitrite formulated sausage.

The addition of carotenoproteins to sausages contributed to high inhibition zones of several gram negative (E. coli, K. pneumoniae, S. enterica, Enterobacter sp., and S. Typhimurium) and gram positive (S. aureus, B. cereus, M. luteus, and $E$. flavus). Low TBARS (1.5-5.5 mg. MDA $/ \mathrm{kg}$ sausages) and diene. Low TBARS (1.5-5.5 mg. dienes formation; his and metmyoglobin contents (up to $\sim 54 \%$ ) were found
manufactured sausages compared to control ones.

Astaxanthin-added patties displayed no differences $(p>0.05)$ in the $\mathrm{pH}$ levels (5.58-5.68) with control patties, but TBARS values were significantly lower $(p<0.05,-21.55$ to $-41.44 \%)$ values were significantly lower $(p<0.05,-21.55$ to -41.4
The developed patties exhibited the same $\mathrm{L}^{*}$ values, but supplement containing $1 \%$ astaxanthin and excipients such as maltodextrin magnesium stearate, and silicon dioxide. Astaxanthins (20,40, and $60 \mathrm{ppm}$ ) were added to ground patties prepared from lamb legs prepared at $5{ }^{\circ} \mathrm{C}$. Fo the cooked patties, antioxidants were added at $4{ }^{\circ} \mathrm{C}$ and left for 5 days, and then the patties were cooked in a convection oven $\left(150^{\circ} \mathrm{C}, 15 \mathrm{~min}\right)$ until the then the patties were higher $\mathrm{a}^{*}$ and $\mathrm{b}^{*}$. The lowest TBARS levels were shown for the astaxanthin-patties, and cooked patties with astaxanthin

7- $\beta$-hydroxycholesterol; 5,6- $\beta$-epoxycholesterol; faecalis) bacteria, and fungi (A. niger, F. oxysporum, and $A$. displayed lower 7- $\alpha$-hydroxycholesterol cholestan-3,5-dien-7-one, and 7-ketocholesterol than control patties. 
Table 2. Cont.

Product

Pigment Origin

Obtention Method and Experimental Procedure

Ref.

Pitaya peels were removed, air-dried $\left(25^{\circ} \mathrm{C}\right)$, milled $(125 \mu \mathrm{m}$ sieve $)$, and stored in amber flasks. A microwave-assisted extraction was conducted by mixing 0.5 of the powder with $25 \mathrm{~mL}$ ethanol $(400 \mathrm{~W}, 30 \mathrm{~s})$, followed by centrifugation $\left(1400 \times g, 15 \mathrm{~min}, 4^{\circ} \mathrm{C}\right)$, and supernatant collection. The resulting extract was concentrated by rotary evaporation $\left(50 \mathrm{rpm}, 60^{\circ} \mathrm{C}\right.$ under vacuum), maltodextrin was added, and the mixture was spray-dried (feed flow: $1 \mathrm{~kg} / \mathrm{h}$, air pressure: $7 \mathrm{bar}$; IAT: $170^{\circ} \mathrm{C}$, OAT: $90^{\circ} \mathrm{C}$ ). The extract was then vacuum packed and frozen $\left(-80^{\circ} \mathrm{C}\right)$. Two concentrations (100 and $1000 \mathrm{ppm}$ ) were added to pork patties prepared from pork loin (Longissium thoracis et lumborum, $82 \%$ lean and $18 \%$ fat).

\section{Other food products}

Carrot (Daucus carota sbsp sativus)

Pasta
Minimally processed carrot residues (peel, shavings, and peduncles) were cleaned (chlorine solution: $200 \mathrm{ppm}, 15 \mathrm{~min})$, ground (125 $\mu \mathrm{m})$, and added to pasta formulations $(10-20 \% w / w)$
Saffron powder was commercially acquired and added $(0.1,0.2$, and $0.4 \%$ $w / w)$ to pasta ( $70 \%$ wheat flour and $30 \%$ water). Saffron dispersions were previously prepared with water and filtered (Whatman $n^{\circ} 40$ paper).

Chopped "Senduduk" (purplish-black color) was blended with water (1:3 water:fruit proportion) and filtered with a gauze. Jackfruit $(45 \mathrm{~g})$ was mixed with sugar, $0.5 \mathrm{~g}$ citric acid, $1 \mathrm{~g}$ pectin, and the blend was boiled and stirred. After cooling $\left(40{ }^{\circ} \mathrm{C}\right)$, and senduku extracts were added $(2-10 \%)$. The product was cooked at $50^{\circ} \mathrm{C}$ for 5 min until jam was formed.

Lutein oleoresin was prepared from the freeze-dried biomass of Muriellopsis sp. at a final concentration of $20 \% w / w$, prepared using vegetable oil. The solution was ultrasound-homogenized (40 oscillations, 6 pulses $/ \mathrm{s}, 10 \mathrm{~min})$
Formulated patties showed the lowest $\mathrm{pH}$ values ( 5.5 to 6.0$)$ higher $L^{*}(11.79-13.61 \%)$, and lower $b^{*}(-4.56$ to $-7.75 \%)$ long storage time ( 9 days). During the same shelf-life analysis, cohesiveness and springiness were preserved in the patties, but hardness and chewiness increased. Overall low TBARS (<3.5 mg MDA/kg meat) were obtained.

Carrot flour mainly contained lutein $(320.98 \mathrm{~g} / 100 \mathrm{~g})$

zeaxanthin $(109.12 \mathrm{~g} / 100 \mathrm{~g})$, cryptoxanthin $(143.75 \mathrm{mg} / \mathrm{g})$, $\alpha$-carotene $(4296.78 \mathrm{~g} / 100 \mathrm{~g}), \beta$-carotene $(4429.77 \mathrm{~g} / 100 \mathrm{~g})$, and retinol $(340.75 \mathrm{~g} / 100 \mathrm{~g})$. Formulated carrot pasta showed [133 higher solid loss (7.55-11.71\%) and weight increase $(216.27-220.49 \%)$, and significantly higher $(p<0.05) \mathrm{DPPH}$ inhibition $(21.02 \%$ vs. $10.01 \%)$ than control pasta.

Saffron-enriched pasta increased $\mathrm{a}^{*}$ and $\mathrm{b}^{*}$ values, decreased uminosity, and did not affect harness, cohesiveness, elasticity, nor chewiness, compared to control pasta. Saffron allowed high DPPH values (0.5-7.0-fold higher than control), and the formulated pasta was positively scored in terms of aspect, color, aroma, taste, and global acceptability.

Senduku provided vitamin C (2.81-3.02 ppm), increased $\mathrm{pH}$ along with concentration (3.4-3.7), and decreased total acidity from jackfruit jam. Moreover, senduku delivered b-carotene, ANC, TPC, and antioxidant capacity

(IC 50 : 83.89-102.01 ppm).

Formulated mayonnaises exhibited higher lutein and pigment stability than commercial mayonnaises.

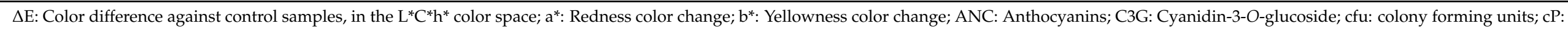

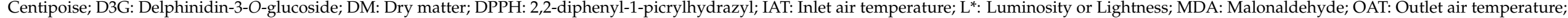

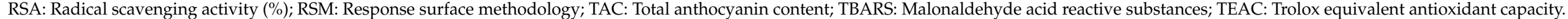




\section{Conclusions and Perspectives}

The use of natural colorants in food systems is still limited due to technological issues. Alternative sources of colorants should be explored, aiming to find more stable, physicochemical feasible, and improved color stability from traditional and novel sources. Underutilized tropical fruits and vegetables such as Andean, Amazonian, and SouthAsian products are still underdeveloped raw materials to extract valuable natural foodcolorants. Emerging technologies such as ohmic heating and EF-based technologies have the advantage of using less energy and water for extracting compounds, whereas PEF easily induces electroporation on the food matrix, accelerating the extraction to reach $<80 \%$ yield for some colorants. For heat-labile compounds, HPE allows the extraction without using temperature, preserving its functional characteristics. However, extraction technologies should be optimized to provide environmentally feasible and low-cost colorants from the actual and novel sources.

Although the addition of some of these novel ingredients might affect the physicochemical properties of these products, as shown in dairy and dairy-like products such as ice creams, optimization procedures improving the existing formulations could positively enhance the inclusion of these nutritionally rich ingredients. Hence, new textures and sensory outcomes could be provided, together with a nutritional advantage derived from the health-associate properties of most of these colorants. Understanding the chemical composition of the natural food-colorants and their interaction with the food matrix is a key factor to manufacture food products with the desired color stability. More research is needed to stabilize most of these colorants at the varied range of the usual $\mathrm{pH}$ and temperature conditions in the intended food systems.

Author Contributions: Conceptualization: D.A.L.-V.; methodology: D.A.L.-V., I.L.-O., A.K.R.-J., and L.M.; validation: D.A.L.-V., I.L.-O., A.K.R.-J., and L.M.; investigation: I.L.-O., A.K.R.-J., L.M., J.Y., and D.A.L.-V.; writing-original draft preparation: I.L.-O., A.K.R.-J., L.M., J.Y., and D.A.L.-V.; writing-review and editing: I.L.-O. and D.A.L.-V.; supervision: D.A.L.-V. All authors have read and agreed to the published version of the manuscript.

Funding: This review was financially supported by a UIC-TEC Seed Fund.

Institutional Review Board Statement: Not applicable.

Informed Consent Statement: Not applicable.

Data Availability Statement: Data are available upon reasonable request.

Acknowledgments: Author I. Luzardo-Ocampo acknowledges Programa de Becas Posdoctorales de la UNAM (DGAPA-CTIC) for his postdoctoral fellowship [grant number: 5267].

Conflicts of Interest: The authors declare no conflict of interest.

\begin{tabular}{|c|c|}
\hline$\Delta \mathrm{E}$ & Color difference against control samples, in the $\mathrm{L}^{*} \mathrm{C}^{*} \mathrm{~h}^{*}$ color space \\
\hline$a^{*}$ & Redness color change in the CIEL ${ }^{*} \mathrm{a}^{*} \mathrm{~b}^{*}$ space \\
\hline ABTS & 2,2-azino-bis(ethylbenzothiazoline-6-sulfonic acid) \\
\hline $\mathrm{a}_{\mathrm{W}}$ & Activity of water \\
\hline ANC & Anthocyanins \\
\hline$b^{*}$ & Yellowness color change in the CIEL* $\mathrm{a}^{*} \mathrm{~b}^{*}$ space \\
\hline$C^{*}$ & Chroma \\
\hline C3G & Cyanidin-3-O-glucoside \\
\hline C3G-Mal & Cyanidin-3-(6'-malonylglucoside) \\
\hline Caco-2 & Human colorectal adenocarcinoma cells \\
\hline $\mathrm{cfu}$ & Colony forming units \\
\hline D3G & Delphinidin-3-O-glucoside \\
\hline $\mathrm{DM}$ & Dry matter \\
\hline DPPH & 2,2-diphenyl-1-picrylhydrazyl \\
\hline
\end{tabular}




\begin{tabular}{|c|c|}
\hline EC3G/L & Equivalents of C3G \\
\hline $\mathrm{EC}_{50}$ & Half-maximal effective concentration \\
\hline EF & Electric field \\
\hline EGCG & Epigallocatechin gallate \\
\hline FRAP & Ferric ion reducing antioxidant power \\
\hline FT-IR & Fourier Transform Infrared \\
\hline GAE & Gallic acid equivalents \\
\hline GC & Gas chromatography \\
\hline GRAS & Generally recognized as safe \\
\hline HepG2 & Human hepatocellular carcinoma cells \\
\hline HHPE & High hydrostatic pressure extraction \\
\hline HPE & High-pressure-assisted extraction \\
\hline IAT & Inlet air temperature \\
\hline$L^{*}$ & Luminosity or lightness in the CIEL ${ }^{*} a^{*} b^{*}$ space \\
\hline MBC & Minimum bactericidal concentration \\
\hline MCF-7 & Human mammary gland/breast adenocarcinoma cells (derived from metastatic site) \\
\hline MDA & Malonaldehyde \\
\hline MDA-MB-231 & Triple negative human mammary gland/breast adenocarcinoma cells \\
\hline MIC & Minimum inhibitory concentration \\
\hline OAT & Outlet air temperature \\
\hline $\mathrm{OH}$ & Ohmic heating \\
\hline P3G & Peonidin-3-(6'-malonylglucoside) \\
\hline P3G-Mal & Pelargonidin-3-(6'-malonylglucoside $)$ \\
\hline $\mathrm{PEF}$ & Pulsed electric fields \\
\hline Pr3G & Pelargonidin-3-O-glucoside \\
\hline RSA & Radical scavenging activity (\%) \\
\hline $\mathrm{SC}-\mathrm{CO}_{2}$ & Supercritical carbon dioxide \\
\hline SFC & Supercritical fluid chromatography \\
\hline SFE & Supercritical fluid extraction \\
\hline TAC & Total anthocyanin content \\
\hline TBARS & Thiobarbituric acid reactive substances \\
\hline TEAC & Trolox equivalent antioxidant capacity \\
\hline TPC & Total phenolic compounds \\
\hline VPR & Vine-pruning residues \\
\hline XR & X-ray \\
\hline
\end{tabular}

\section{References}

1. Nwoba, E.G.; Ogbonna, C.N.; Ishika, T.; Vadiveloo, A. Microalgal Pigments: A Source of Natural Food Colors. In Microalgae Biotechnology for Food, Health and High Value Products; Asraful Alam, M., Xu, J.-L., Wang, Z., Eds.; Springer: Singapore, 2020; pp. 81-123.

2. $\quad$ Albuquerque, B.R.; Oliveira, M.B.P.P.; Barros, L.; Ferreira, I.C.F.R. Could fruits be a reliable source of food colorants? Pros and cons of these natural additives. Crit. Rev. Food Sci. Nutr. 2020, 1-31. [CrossRef] [PubMed]

3. Oplatowska-Stachowiak, M.; Elliott, C.T. Food colors: Existing and emerging food safety concerns. Crit. Rev. Food Sci. Nutr. 2017, 57, 524-548. [CrossRef] [PubMed]

4. Rodriguez-Amaya, D.B. Natural food pigments and colorants. Curr. Opin. Food Sci. 2016, 7, 20-26. [CrossRef]

5. Lin, W.-S.; He, P.H.; Chau, C.-F.; Liou, B.-K.; Li, S.; Pan, M.-H. The feasibility study of natural pigments as food colorants and seasonings pigments safety on dried tofu coloring. Food Sci. Hum. Wellness 2018, 7, 220-228. [CrossRef]

6. Fernández-López, J.A.; Fernández-Lledó, V.; Angosto, J.M. New insights into red plant pigments: More than just natural colorants. RSC Adv. 2020, 10, 24669-24682. [CrossRef]

7. Sigurdson, G.T.; Tang, P.; Giusti, M.M. Natural Colorants: Food Colorants from Natural Sources. Annu. Rev. Food Sci. Technol. 2017, 8, 261-280. [CrossRef]

8. Martins, N.; Roriz, C.L.; Morales, P.; Barros, L.; Ferreira, I.C.F.R. Food colorants: Challenges, opportunities and current desires of agro-industries to ensure consumer expectations and regulatory practices. Trends Food Sci. Technol. 2016, 52, 1-15. [CrossRef]

9. Hidalgo, A.; Brandolini, A.; Čanadanović-Brunet, J.; Ćetković, G.; Tumbas Šaponjac, V. Microencapsulates and extracts from red beetroot pomace modify antioxidant capacity, heat damage and colour of pseudocereals-enriched einkorn water biscuits. Food Chem. 2018, 268, 40-48. [CrossRef]

10. Labuschagne, P. Impact of wall material physicochemical characteristics on the stability of encapsulated phytochemicals: A review. Food Res. Int. 2018, 107, 227-247. [CrossRef] [PubMed] 
11. Chung, C.; Rojanasasithara, T.; Mutilangi, W.; McClements, D.J. Enhanced stability of anthocyanin-based color in model beverage systems through whey protein isolate complexation. Food Res. Int. 2015, 76, 761-768. [CrossRef]

12. Cortez, R.; Luna-Vital, D.A.; Margulis, D.; Gonzalez de Mejia, E. Natural Pigments: Stabilization Methods of Anthocyanins for Food Applications. Compr. Rev. Food Sci. Food Saf. 2017, 16, 180-198. [CrossRef]

13. Chung, C.; Rojanasasithara, T.; Mutilangi, W.; McClements, D.J. Stabilization of natural colors and nutraceuticals: Inhibition of anthocyanin degradation in model beverages using polyphenols. Food Chem. 2016, 212, 596-603. [CrossRef]

14. Rodriguez-Amaya, D.B. Natural Food Pigments and Colorants. In Bioactive Molecules in Food; Mérillon, J.-M., Ramawat, K.G., Eds.; Springer Nature Switzerland AG: Cham, Switzerland, 2019; pp. 867-901.

15. Potera, C. Diet and nutrition: The Artificial Food Dye Blues. Environ. Health Perspect. 2010, 118, A428. [CrossRef]

16. Hsieh-Lo, M.; Castillo, G.; Ochoa-Becerra, M.A.; Mojica, L. Phycocyanin and phycoerythrin: Strategies to improve production yield and chemical stability. Algal Res. 2019, 42, 101600. [CrossRef]

17. Wallace, T.C.; Giusti, M.M. Anthocyanins. Adv. Nutr. 2015, 6, 620-622. [CrossRef] [PubMed]

18. Mazza, G. Anthocyanins in Fruits, Vegetables, and Grains; Routledge: Boca Raton, FL, USA, 2018.

19. Khoo, H.E.; Azlan, A.; Tang, S.T.; Lim, S.M. Anthocyanidins and anthocyanins: Colored pigments as food, pharmaceutical ingredients, and the potential health benefits. Food Nutr. Res. 2017, 61, 1361779. [CrossRef]

20. Bendokas, V.; Skemiene, K.; Trumbeckaite, S.; Stanys, V.; Passamonti, S.; Borutaite, V.; Liobikas, J. Anthocyanins: From plant pigments to health benefits at mitochondrial level. Crit. Rev. Food Sci. Nutr. 2020, 60, 3352-3365. [CrossRef] [PubMed]

21. de Mejia, E.G.; Zhang, Q.; Penta, K.; Eroglu, A.; Lila, M.A. The Colors of Health: Chemistry, Bioactivity, and Market Demand for Colorful Foods and Natural Food Sources of Colorants. Annu. Rev. Food Sci. Technol. 2020, 11, 145-182. [CrossRef]

22. Food-Info E163: Anthocyanins. Available online: http://www.food-info.net/uk/colour/anthocyanin.htm (accessed on 20 February 2020).

23. Li, D.; Wang, P.; Luo, Y.; Zhao, M.; Chen, F. Health benefits of anthocyanins and molecular mechanisms: Update from recent decade. Crit. Rev. Food Sci. Nutr. 2017, 57, 1729-1741. [CrossRef] [PubMed]

24. Luna-Vital, D.; Weiss, M.; Gonzalez de Mejia, E. Anthocyanins from purple corn ameliorated Tumor Necrosis Factor- $\alpha$-induced inflammation and insulin resistance in 3T3-L1 adipocytes via activation of insulin signaling and enhanced GLUT4 translocation. Mol. Nutr. Food Res. 2017, 61,1-13. [CrossRef]

25. Arango-Varela, S.S.; Luzardo-Ocampo, I.; Maldonado-Celis, M.E.; Campos-Vega, R. Andean berry (Vaccinium meridionale Swartz) juice in combination with Aspirin modulated anti-inflammatory markers on LPS-stimulated RAW 264.7 macrophages. Food Res. Int. 2020, 137, 109541. [CrossRef] [PubMed]

26. Eletr, A.A.; Siliha, H.A.E.; Elshobargy, G.A.; Galal, G.A. Evaluation of lycopene extracted from tomato processing waste as a natural antioxidant in some bakery products. Zagazig J. Agric. Res. 2017, 44, 1389-1401.

27. Meléndez-Martínez, A.J. An Overview of Carotenoids, Apocarotenoids, and Vitamin A in Agro-Food, Nutrition, Health, and Disease. Mol. Nutr. Food Res. 2019, 63, 1801045. [CrossRef]

28. Hammond, B.R.; Miller, L.S.; Bello, M.O.; Lindbergh, C.A.; Mewborn, C.; Renzi-Hammond, L.M. Effects of Lutein/Zeaxanthin Supplementation on the Cognitive Function of Community Dwelling Older Adults: A Randomized, Double-Masked, PlaceboControlled Trial. Front. Aging Neurosci. 2017, 9, 254. [CrossRef]

29. Jacob-Lopes, E.; Queiroz, M.I.; Queiroz Zepka, L. Pigments from Microalgae Handbook; Jacob-Lopes, E., Queiroz, M.I., Zepka, L.Q., Eds.; Springer International Publishing: Berlin/Heidelberg, Germany, 2020; ISBN 978-3-030-50970-5.

30. Lourenço-Lopes, C.; Garcia-Oliveira, P.; Carpena, M.; Fraga-Corral, M.; Jimenez-Lopez, C.; Pereira, A.G.; Prieto, M.A.; SimalGandara, J. Scientific Approaches on Extraction, Purification and Stability for the Commercialization of Fucoxanthin Recovered from Brown Algae. Foods 2020, 9, 1113. [CrossRef]

31. Rodriguez-Amaya, D.B. Food Carotenoids; Rodríguez-Amaya, D., Ed.; John Wiley \& Sons, Ltd.: Chichester, UK, 2015; ISBN 9781118864364 .

32. Khan, M.I. Plant Betalains: Safety, Antioxidant Activity, Clinical Efficacy, and Bioavailability. Compr. Rev. Food Sci. Food Saf. 2016, 15, 316-330. [CrossRef]

33. Mosquera, N.; Cejudo-Bastante, M.J.; Heredia, F.J.; Hurtado, N. Identification of New Betalains in Separated Betacyanin and Betaxanthin Fractions from Ulluco (Ullucus tuberosus Caldas) by HPLC-DAD-ESI-MS. Plant. Foods Hum. Nutr. 2020, 75, 434-440. [CrossRef]

34. Rodríguez-Sánchez, J.A.; Cruz y Victoria, M.T.; Barragán-Huerta, B.E. Betaxanthins and antioxidant capacity in Stenocereus pruinosus: Stability and use in food. Food Res. Int. 2017, 91, 63-71. [CrossRef] [PubMed]

35. Kang, Y.-R.; Park, J.; Jung, S.K.; Chang, Y.H. Synthesis, characterization, and functional properties of chlorophylls, pheophytins, and Zn-pheophytins. Food Chem. 2018, 245, 943-950. [CrossRef]

36. Subramoniam, A.; Asha, V.V.; Nair, S.A.; Sasidharan, S.P.; Sureshkumar, P.K.; Rajendran, K.N.; Karunagaran, D.; Ramalingam, K. Chlorophyll Revisited: Anti-inflammatory Activities of Chlorophyll a and Inhibition of Expression of TNF- $\alpha$ Gene by the Same. Inflammation 2012, 35, 959-966. [CrossRef]

37. Viera, I.; Pérez-Gálvez, A.; Roca, M. Green Natural Colorants. Molecules 2019, 24, 154. [CrossRef] [PubMed]

38. Jiang, L.; Wang, Y.; Yin, Q.; Liu, G.; Liu, H.; Huang, Y.; Li, B. Phycocyanin: A Potential Drug for Cancer Treatment. J. Cancer 2017, 8, 3416-3429. [CrossRef] [PubMed] 
39. Zhang, Z.; Cho, S.; Dadmohammadi, Y.; Li, Y.; Abbaspourrad, A. Improvement of the storage stability of C-phycocyanin in beverages by high-pressure processing. Food Hydrocoll. 2021, 110, 106055. [CrossRef]

40. Pereira, R.N.; Rodrigues, R.M.; Genisheva, Z.; Oliveira, H.; de Freitas, V.; Teixeira, J.A.; Vicente, A.A. Effects of ohmic heating on extraction of food-grade phytochemicals from colored potato. LWT 2016, 74, 493-503. [CrossRef]

41. El Darra, N.; Grimi, N.; Vorobiev, E.; Louka, N.; Maroun, R. Extraction of Polyphenols from Red Grape Pomace Assisted by Pulsed Ohmic Heating. Food Bioprocess. Technol. 2013, 6, 1281-1289. [CrossRef]

42. Sakr, M.; Liu, S. A comprehensive review on applications of ohmic heating (OH). Renew. Sustain. Energy Rev. 2014, 39, 262-269. [CrossRef]

43. Brochier, B.; Mercali, G.D.; Marczak, L.D.F. Effect of moderate electric field on peroxidase activity, phenolic compounds and color during ohmic heating of sugarcane juice. J. Food Process. Preserv. 2019, 43, 1-10. [CrossRef]

44. Saeed Al-Hilphy, A.R.; Jabeer AlRikabi, A.K.; Al-Salim, A.M. Extraction of phenolic compounds from wheat bran using ohmic heating. Food Sci. Qual. Manag. 2015, 43, 21-30.

45. Loypimai, P.; Moongngarm, A.; Chottanom, P.; Moontree, T. Ohmic heating-assisted extraction of anthocyanins from black rice bran to prepare a natural food colourant. Innov. Food Sci. Emerg. Technol. 2015, 27, 102-110. [CrossRef]

46. Sarkis, J.R.; Jaeschke, D.P.; Tessaro, I.C.; Marczak, L.D.F. Effects of ohmic and conventional heating on anthocyanin degradation during the processing of blueberry pulp. LWT Food Sci. Technol. 2013, 51, 79-85. [CrossRef]

47. Pereira, R.N.; Souza, B.W.S.; Cerqueira, M.A.; Teixeira, J.A.; Vicente, A.A. Effects of Electric Fields on Protein Unfolding and Aggregation: Influence on Edible Films Formation. Biomacromolecules 2010, 11, 2912-2918. [CrossRef] [PubMed]

48. Jesus, M.S.; Ballesteros, L.F.; Pereira, R.N.; Genisheva, Z.; Carvalho, A.C.; Pereira-Wilson, C.; Teixeira, J.A.; Domingues, L. Ohmic heating polyphenolic extracts from vine pruning residue with enhanced biological activity. Food Chem. 2020, 316, 126298. [CrossRef]

49. Aguilar-Machado, D.; Morales-Oyervides, L.; Contreras-Esquivel, J.C.; Aguilar, C.; Méndez-Zavala, A.; Raso, J.; Montañez, J. Effect of ohmic heating processing conditions on color stability of fungal pigments. Food Sci. Technol. Int. 2017, 23, 338-348. [CrossRef] [PubMed]

50. Zimmermann, U.; Pilwat, G.; Riemann, F. Dielectric Breakdown of Cell Membranes. In Membrane Transport in Plants; Zimmermann, U., Dainty, J., Eds.; Springer: Berlin/Heidelberg, Germany, 1974; pp. 146-153.

51. Kumari, B.; Tiwari, B.K.; Hossain, M.B.; Brunton, N.P.; Rai, D.K. Recent Advances on Application of Ultrasound and Pulsed Electric Field Technologies in the Extraction of Bioactives from Agro-Industrial By-products. Food Bioprocess. Technol. 2018, 11, 223-241. [CrossRef]

52. He, Y.; Wen, L.; Liu, J.; Li, Y.; Zheng, F.; Min, W.; Yue, H.; Pan, P. Optimisation of pulsed electric fields extraction of anthocyanin from Beibinghong Vitis Amurensis Rupr. Nat. Prod. Res. 2018, 32, 23-29. [CrossRef]

53. Puértolas, E.; Cregenzán, O.; Luengo, E.; Álvarez, I.; Raso, J. Pulsed-electric-field-assisted extraction of anthocyanins from purple-fleshed potato. Food Chem. 2013, 136, 1330-1336. [CrossRef] [PubMed]

54. Loginova, K.V.; Lebovka, N.I.; Vorobiev, E. Pulsed electric field assisted aqueous extraction of colorants from red beet. J. Food Eng. 2011, 106, 127-133. [CrossRef]

55. Martínez, J.M.; Gojkovic, Z.; Ferro, L.; Maza, M.; Álvarez, I.; Raso, J.; Funk, C. Use of pulsed electric field permeabilization to extract astaxanthin from the Nordic microalga Haematococcus pluvialis. Bioresour. Technol. 2019, 289, 121694. [CrossRef]

56. Martínez, J.M.; Delso, C.; Álvarez, I.; Raso, J. Pulsed electric field permeabilization and extraction of phycoerythrin from Porphyridium cruentum. Algal Res. 2019, 37, 51-56. [CrossRef]

57. Zhang, Z.-H.; Wang, L.-H.; Zeng, X.-A.; Han, Z.; Wang, M.-S. Effect of pulsed electric fields (PEFs) on the pigments extracted from spinach (Spinacia oleracea L.). Innov. Food Sci. Emerg. Technol. 2017, 43, 26-34. [CrossRef]

58. Mandal, R.; Kant, R. High-pressure processing and its applications in the dairy industry. Food Sci. Technol. An. Int. J. 2017, 1, 33-45.

59. Ghafoor, K.; Gavahian, M.; Marszałek, K.; Barba, F.J.; Xia, Q.; Denoya, G.I. An overview of the potential applications based on HPP mechanism. In Present and Future of High Pressure Processing; Barba, F., Tonello-Samson, C., Puértolas, E., Lavilla, M., Eds.; Elsevier: Amsterdam, The Netherlands, 2020; pp. 3-11, ISBN 9780128164051.

60. Alexandre, E.M.C.; Araújo, P.; Duarte, M.F.; de Freitas, V.; Pintado, M.; Saraiva, J.A. Experimental Design, Modeling, and Optimization of High-Pressure-Assisted Extraction of Bioactive Compounds from Pomegranate Peel. Food Bioprocess. Technol. 2017, 10, 886-900. [CrossRef]

61. Seabra, I.J.; Braga, M.E.M.; Batista, M.T.P.; de Sousa, H.C. Fractioned High Pressure Extraction of Anthocyanins from Elderberry (Sambucus nigra L.) Pomace. Food Bioprocess. Technol. 2010, 3, 674-683. [CrossRef]

62. Luna-Vital, D.; Cortez, R.; Ongkowijoyo, P.; Gonzalez de Mejia, E. Protection of color and chemical degradation of anthocyanin from purple corn (Zea mays L.) by zinc ions and alginate through chemical interaction in a beverage model. Food Res. Int. 2018, 105, 169-177. [CrossRef]

63. Luna-Vital, D.; Luzardo-Ocampo, I.; Cuellar-Nuñez, L.; Loarca-Pina, G.; de Mejia, E.G. Maize extract rich in ferulic acid and anthocyanins prevents high-fat induced obesity in mice by modulating SIRT1, AMPK, and IL-6 associated metabolic and inflammatory pathways. J. Nutr. Biochem. 2020, 91, 108343. [CrossRef] [PubMed]

64. Putnik, P.; Bursać Kovačević, D.; Ježek, D.; Šustić, I.; Zorić, Z.; Dragović-Uzelac, V. High-pressure recovery of anthocyanins from grape skin pomace ( Vitis vinifera cv. Teran) at moderate temperature. J. Food Process. Preserv. 2018, 42, e13342. [CrossRef] 
65. Haining, Z.; Yongkun, M. Optimisation of High Hydrostatic Pressure Assisted Extraction of Anthocyanins from Rabbiteye Blueberry Pomace. Czech. J. Food Sci. 2017, 35, 180-187. [CrossRef]

66. Ibáñez, E.; Mendiola, J.A.; Castro-Puyana, M. Supercritical Fluid Extraction. In Encyclopedia of Food and Health; Caballero, B., Finglas, P.M., Toldrá, F., Eds.; Elsevier: Amsterdam, The Netherlands, 2016; pp. 227-233, ISBN 978-0-12-384953-3.

67. Abhari, K.; Mousavi Khaneghah, A. Alternative extraction techniques to obtain, isolate and purify proteins and bioactive from aquaculture and by-products. In Aquaculture and By-Products: Challenges and Opportunities in the Use of Alternative Protein Sources and Bioactive Compounds; Lorenzo, J.M., Barba, F.J., Eds.; Elsevier: Amsterdam, The Netherlands, 2020; pp. 35-52, ISBN 978-0-12-820216-6.

68. da Silva, R.P.F.F.; Rocha-Santos, T.A.P.; Duarte, A.C. Supercritical fluid extraction of bioactive compounds. TrAC Trends Anal. Chem. 2016, 76, 40-51. [CrossRef]

69. Sapkale, G.N.; Patil, S.M.; Surwase, U.S.; Bhatbhage, P.K. Supercritical fluid extraction. A review. Int. J. Chem. Sci. 2010, 8, 729-743.

70. Jiao, G. Kermanshahi pour, A. Extraction of anthocyanins from haskap berry pulp using supercritical carbon dioxide: Influence of co-solvent composition and pretreatment. LWT 2018, 98, 237-244. [CrossRef]

71. Idham, Z.; Zaini, A.S.; Putra, N.R.; Rusli, N.M.; Mahat, N.S.; Yian, L.N.; Che Yunus, M.A. Effect of flow rate, particle size and modifier ratio on the supercritical fluid extraction of anthocyanins from Hibiscus sabdariffa (L). IOP Conf. Ser. Mater. Sci. Eng. 2020, 932, 012031. [CrossRef]

72. Seremet (Ceclu), L.; Nistor, O.-V.; Andronoiu, D.G.; Mocanu, G.D.; Barbu, V.V.; Maidan, A.; Rudi, L.; Botez, E. Development of several hybrid drying methods used to obtain red beetroot powder. Food Chem. 2020, 310, 125637. [CrossRef]

73. Abdel-Moemin, A.R. Effect of Roselle calyces extract on the chemical and sensory properties of functional cupcakes. Food Sci. Hum. Wellness 2016, 5, 230-237. [CrossRef]

74. Amjadi, S.; Ghorbani, M.; Hamishehkar, H.; Roufegarinejad, L. Improvement in the stability of betanin by liposomal nanocarriers: Its application in gummy candy as a food model. Food Chem. 2018, 256, 156-162. [CrossRef]

75. Carballo, D.E.; Caro, I.; Andrés, S.; Giráldez, F.J.; Mateo, J. Assessment of the antioxidant effect of astaxanthin in fresh, frozen and cooked lamb patties. Food Res. Int. 2018, 111, 342-350. [CrossRef] [PubMed]

76. da Silva, L.P.; Pereira, E.; Prieto, M.A.; Simal-Gandara, J.; Pires, T.C.S.P.; Alves, M.J.; Calhelha, R.; Barros, L.; Ferreira, I.C.F.R. Rubus ulmifolius Schott as a Novel Source of Food Colorant: Extraction Optimization of Coloring Pigments and Incorporation in a Bakery Product. Molecules 2019, 24, 2181. [CrossRef]

77. Montoya-Rodríguez, A.; Milán-Carrillo, J.; Dia, V.P.; Reyes-Moreno, C.; González de Mejía, E. Pepsin-pancreatin protein hydrolysates from extruded amaranth inhibit markers of atherosclerosis in LPS-induced THP-1 macrophages-like human cells by reducing expression of proteins in LOX-1 signalling pathway. Proteome Sci. 2014, 12, 30. [CrossRef]

78. Freitas-Sá, D.D.G.C.; de Souza, R.C.; de Araujo, M.C.P.; Borguini, R.G.; de Mattos, L.D.S.; Pacheco, S.; de Godoy, R.L.O. Effect of jabuticaba (Myrciaria jaboticaba (Vell) O. Berg) and jamelão (Syzygium cumini (L.) Skeels) peel powders as colorants on color-flavor congruence and acceptability of yogurts. LWT 2018, 96, 215-221. [CrossRef]

79. López, C.J.; Caleja, C.; Prieto, M.A.; Sokovic, M.; Calhelha, R.C.; Barros, L.; Ferreira, I.C.F.R. Stability of a cyanidin-3-O-glucoside extract obtained from Arbutus unedo L. and incorporation into wafers for colouring purposes. Food Chem. 2019, 275, 426-438. [CrossRef] [PubMed]

80. Sharma, P.; Segat, A.; Kelly, A.L.; Sheehan, J.J. Colorants in cheese manufacture: Production, chemistry, interactions, and regulation. Compr. Rev. Food Sci. Food Saf. 2020, 19, 1220-1242. [CrossRef] [PubMed]

81. Albuquerque, B.R.; Pinela, J.; Barros, L.; Oliveira, M.B.P.P.; Ferreira, I.C.F.R. Anthocyanin-rich extract of jabuticaba epicarp as a natural colorant: Optimization of heat- and ultrasound-assisted extractions and application in a bakery product. Food Chem. 2020, 316, 126364. [CrossRef]

82. Aziz, A.A.; Modh Padzil, A.; Muhamad, I.I. Effects of incorporating purple-flashed sweet potato in biscuit on antioxidant content, antioxidant capacity, and colour characteristics. Malaysian J. Anal. Sci. 2018, 22, 665-667. [CrossRef]

83. Croitoru, C.; Mureșan, C.; Turturică, M.; Stănciuc, N.; Andronoiu, D.; Dumitrașcu, L.; Barbu, V.; Enachi (Ioniță), E.; Horincar (Parfene), G.; Râpeanu, G. Improvement of Quality Properties and Shelf Life Stability of New Formulated Muffins Based on Black Rice. Molecules 2018, 23, 3047. [CrossRef]

84. Harnly, J. Antioxidant methods. J. Food Compos. Anal. 2017, 64, 145-146. [CrossRef]

85. Vinha, A.F.; Rodrigues, F.; Nunes, M.A.; Oliveira, M.B.P.P. Natural pigments and colorants in foods and beverages. In Polyphenols: Properties, Recovery, and Applications; Galanakis, C.M., Ed.; Woodhead Publishing: Cambridge, UK, 2018; pp. 363-391, ISBN 978-0-12-813572-3.

86. Quilaqueo, M.; Millao, S.; Luzardo-Ocampo, I.; Campos-Vega, R.; Acevedo, F.; Shene, C.; Rubilar, M. Inclusion of piperine in $\beta$-cyclodextrin complexes improves their bioaccessibility and in vitro antioxidant capacity. Food Hydrocoll. 2019, 91, 143-152. [CrossRef]

87. Aguilera, Y.; Mojica, L.; Rebollo-Hernanz, M.; Berhow, M.; De Mejía, E.G.; Martín-Cabrejas, M.A. Black bean coats: New source of anthocyanins stabilized by $\beta$-cyclodextrin copigmentation in a sport beverage. Food Chem. 2016, 212, 561-570. [CrossRef] [PubMed] 
88. Lobo, F.A.T.; Silva, V.; Domingues, J.; Rodrigues, S.; Costa, V.; Falcão, D.; de Lima Araújo, K.G. Inclusion complexes of yellow bell pepper pigments with $\beta$-cyclodextrin: Preparation, characterisation and application as food natural colorant. J. Sci. Food Agric. 2018, 98, 2665-2671. [CrossRef] [PubMed]

89. Carmona, J.C.; Fabry, A.M.; Sáenz, C. Coloring foods from yellow-orange cactus pear. Acta Hortic. 2019, 15-22. [CrossRef]

90. Giménez, P.J.; Fernández-López, J.A.; Angosto, J.M.; Obón, J.M. Comparative Thermal Degradation Patterns of Natural Yellow Colorants Used in Foods. Plant. Foods Hum. Nutr. 2015, 70, 380-387. [CrossRef]

91. Cerreti, M.; Liburdi, K.; Del Franco, F.; Esti, M. Heat and light stability of natural yellow colourants in model beverage systems. Food Addit. Contam. Part A 2020, 37, 905-915. [CrossRef] [PubMed]

92. Chatham, L.A.; Howard, J.E.; Juvik, J.A. A natural colorant system from corn: Flavone-anthocyanin copigmentation for altered hues and improved shelf life. Food Chem. 2020, 310, 125734. [CrossRef]

93. De Gomes Rocha, J.C.; Coutinho Viana, K.W.; Corrêa Mendonç, A.A.; de Andrade Neves, N.; Fernandes de Carvalho, A.; Rodrigues Minim, V.P.; Ribeiro de Barros, F.A.; Stringheta, P.C. Protein beverages containing anthocyanins of jabuticaba. Food Sci. Technol. 2019, 39, 112-119. [CrossRef]

94. Tensiska, T.; Marta, H.; Cahyana, Y.; Amirah, N.S. Application of Encapsulated Anthocyanin Pigments from Purple Sweet Potato (Ipomoea Batatas L.) in Jelly Drink. KnE Life Sci. 2017, 2, 482. [CrossRef]

95. Dufossé, L.; Galaup, P.; Yaron, A.; Arad, S.M.; Blanc, P.; Chidambara Murthy, K.N.; Ravishankar, G.A. Microorganisms and microalgae as sources of pigments for food use: A scientific oddity or an industrial reality? Trends Food Sci. Technol. 2005, 16, 389-406. [CrossRef]

96. Petruzzi, L.; Campaniello, D.; Speranza, B.; Corbo, M.R.; Sinigaglia, M.; Bevilacqua, A. Thermal Treatments for Fruit and Vegetable Juices and Beverages: A Literature Overview. Compr. Rev. Food Sci. Food Saf. 2017, 16, 668-691. [CrossRef]

97. Suryanarayana, R.; Chandrappa, M.; Santhosh, R. Awareness of use of artificial colourants in sweets preparation and their harmful effects. Int. J. Community Med. Public Health 2017, 4, 3893. [CrossRef]

98. Backes, E.; Leichtweis, M.G.; Pereira, C.; Carocho, M.; Barreira, J.C.M.; Kamal Genena, A.; José Baraldi, I.; Filomena Barreiro, M.; Barros, L.; Ferreira, I.C.F.R. Ficus carica L. and Prunus spinosa L. extracts as new anthocyanin-based food colorants: A thorough study in confectionery products. Food Chem. 2020, 333, 127457. [CrossRef]

99. Otálora, M.C.; de Jesús Barbosa, H.; Perilla, J.E.; Osorio, C.; Nazareno, M.A. Encapsulated betalains (Opuntia ficus-indica) as natural colorants. Case study: Gummy candies. LWT 2019, 103, 222-227. [CrossRef]

100. Chranioti, C.; Nikoloudaki, A.; Tzia, C. Saffron and beetroot extracts encapsulated in maltodextrin, gum Arabic, modified starch and chitosan: Incorporation in a chewing gum system. Carbohydr. Polym. 2015, 127, 252-263. [CrossRef]

101. Quintero-Castaño, V.D.; Vasco-Leal, J.F.; Cuellar-Nuñez, L.; Luzardo-Ocampo, I.; Castellanos-Galeano, F.; Álvarez-Barreto, C.; Bello-Pérez, L.A.; Cortés-Rodriguez, M. Novel OSA-Modified Starch from Gros Michel Banana for Encapsulation of Andean Blackberry Concentrate: Production and Storage Stability. Starch Stärke 2020, 2000180, in press. [CrossRef]

102. Da Silva, L.B.; Queiroz, M.B.; Fadini, A.L.; da Fonseca, R.C.C.; Germer, S.P.M.; Efraim, P. Chewy candy as a model system to study the influence of polyols and fruit pulp (açai) on texture and sensorial properties. LWT Food Sci. Technol. 2016, 65, 268-274. [CrossRef]

103. Hartel, R.W.; von Elbe, J.H.; Hofberger, R. Sugar and Sugar-Free Panned Confections. In Confectionery Science and Technology; Hartel, R.W., von Elbe, J.H., Hofberger, R., Eds.; Springer International Publishing: New York, NY, USA, 2018; pp. 361-391, ISBN 978-3-319-61740-4.

104. Hubbermann, E.M. Coloring of Low-Moisture and Gelatinized Food Products. In Handbook on Natural Pigments in Food and Beverages; Carle, R., Schweiggert, R.M., Eds.; Woodhead Publishing: Cambridge, UK, 2016; pp. 179-196, ISBN 978-0-08-100371-8.

105. Avelar, M.H.M.; Silva, L.B.; Azevedo, F.B.; Efraim, P. A byproduct of uvaia (Eugenia pyriformis) processing as a natural source for coloring sugar hard-panning confections. J. Food Process. Eng. 2019, 42. [CrossRef]

106. Małgorzata, D.; Aleksandra, P.; Monika, T.; Ireneusz, K. A New Black Elderberry Dye Enriched in Antioxidants Designed for Healthy Sweets Production. Antioxidants 2019, 8, 257. [CrossRef] [PubMed]

107. Durmaz, Y.; Bandarra, N.M. Fatty acids and pigments content of Nannochloropsis oculata(Eustigmatophyceae) culture at bag systems using different nitrogen sources and concentration in medium. Fresenius Environ. Bull. 2017, 36, 5289-5294.

108. Genc Polat, D.; Durmaz, Y.; Konar, N.; Toker, O.S.; Palabiyik, I.; Tasan, M. Using encapsulated Nannochloropsis oculata in white chocolate as coloring agent. J. Appl. Phycol. 2020, 32, 3077-3088. [CrossRef]

109. Herrera-Cazares, L.A.; Hernández-Navarro, F.; Ramírez-Jiménez, A.K.; Campos-Vega, R.; de la Reyes-Vega, M.L.; Loarca-Piña, G.; Morales-Sánchez, E.; Wall-Medrano, A.; Gaytán-Martínez, M. Mango-bagasse functional-confectionery: Vehicle for enhancing bioaccessibility and permeability of phenolic compounds. Food Funct. 2017, 8, 3906-3916. [CrossRef] [PubMed]

110. Gawai, K.M.; Mudgal, S.P.; Prajapati, J.B. Stabilizers, Colorants, and Exopolysaccharides in Yogurt. In Yogurt in Health and Disease Prevention; Shah, N.P., Ed.; Elsevier: Amsterdam, The Netherlands, 2017; pp. 49-68, ISBN 978-0-12-805134-4.

111. Caldas-Cueva, J.P.; Morales, P.; Ludeña, F.; Betalleluz-Pallardel, I.; Chirinos, R.; Noratto, G.; Campos, D. Stability of Betacyanin Pigments and Antioxidants in Ayrampo (Opuntia soehrensii Britton and Rose) Seed Extracts and as a Yogurt Natural Colorant. J. Food Process. Preserv. 2016, 40, 541-549. [CrossRef]

112. Almeida, H.H.S.; Barros, L.; Barreira, J.C.M.; Calhelha, R.C.; Heleno, S.A.; Sayer, C.; Miranda, C.G.; Leimann, F.V.; Barreiro, M.F.; Ferreira, I.C.F.R. Bioactive evaluation and application of different formulations of the natural colorant curcumin (E100) in a hydrophilic matrix (yogurt). Food Chem. 2018, 261, 224-232. [CrossRef] [PubMed] 
113. Pires, T.C.S.P.; Dias, M.I.; Barros, L.; Barreira, J.C.M.; Santos-Buelga, C.; Ferreira, I.C.F.R. Incorporation of natural colorants obtained from edible flowers in yogurts. LWT 2018, 97, 668-675. [CrossRef]

114. Benchikh, Y.; Aissaoui, A.; Allouch, R.; Mohellebi, N. Optimising anthocyanin extraction from strawberry fruits using response surface methodology and application in yoghurt as natural colorants and antioxidants. J. Food Sci. Technol. 2020, in press. [CrossRef]

115. Dias, S.; Castanheira, E.M.S.; Fortes, A.G.; Pereira, D.M.; Gonçalves, M.S.T. Natural Pigments of Anthocyanin and Betalain for Coloring Soy-Based Yogurt Alternative. Foods 2020, 9, 771. [CrossRef]

116. Arab, M.; Razavi, S.H.; Hosseini, S.M.; Nayebzadeh, K.; Meybodi, N.M.; Khanniri, E.; Mardi, P.; Mortazavian, A.M. Production and characterization of functional flavored milk and flavored fermented milk using microencapsulated canthaxanthin. LWT 2019, 114, 108373. [CrossRef]

117. Montibeller, M.J.; de Lima Monteiro, P.; Tupuna-Yerovi, D.S.; de Rios, A.O.; Manfroi, V. Stability assessment of anthocyanins obtained from skin grape applied in kefir and carbonated water as a natural colorant. J. Food Process. Preserv. 2018, 42 , e13698. [CrossRef]

118. Ilansuriyan, P.; Shanmugam, M. Rheological, physiochemical, and sensory properties of no fat to high fat ice cream samples using stabilizer/emulsifier blends created with liquid and powder polisorbate-80. Int. Food Res. J. 2018, 25, $2579-2584$.

119. Krahl, T.; Fuhrmann, H.; Dimassi, S. Ice Cream. In Handbook on Natural Pigments in Food and Beverages; Carle, R., Schweiggert, R.M., Eds.; Elsevier: Amsterdam, The Netherlands, 2016; pp. 197-207, ISBN 978-0-08-100392-3.

120. Singo, T.; Beswa, D. Effect of roselle extracts on the selected quality characteristics of ice cream. Int. J. Food Prop. 2019, $22,42-53$. [CrossRef]

121. Durmaz, Y.; Kilicli, M.; Toker, O.S.; Konar, N.; Palabiyik, I.; Tamtürk, F. Using spray-dried microalgae in ice cream formulation as a natural colorant: Effect on physicochemical and functional properties. Algal Res. 2020, 47, 101811. [CrossRef]

122. Gengatharan, A.; Dykes, G.; Choo, W.S. Betacyanins from Hylocereus polyrhizus: Pectinase-assisted extraction and application as a natural food colourant in ice cream. J. Food Sci. Technol. 2020, in press. [CrossRef]

123. Carter, B.G.; Park, C.W.; Drake, M.A. Short communication: Sensitive detection of norbixin in dried dairy ingredients at concentrations of less than 1 part per billion. J. Dairy Sci. 2017, 100, 8754-8758. [CrossRef]

124. Aktypis, A.; Christodoulou, E.D.; Manolopoulou, E.; Georgala, A.; Daferera, D.; Polysiou, M. Fresh ovine cheese supplemented with saffron (Crocus sativus L.): Impact on microbiological, physicochemical, antioxidant, color and sensory characteristics during storage. Small Rumin. Res. 2018, 167, 32-38. [CrossRef]

125. Ghendov-Moşanu, A.; Sturza, R.; Opriş, O.; Lung, I.; Popescu, L.; Popovici, V.; Soran, M.-L.; Patraş, A. Effect of lipophilic sea buckthorn extract on cream cheese properties. J. Food Sci. Technol. 2020, 57, 628-637. [CrossRef]

126. de Moura, S.C.S.R.; Schettini, G.N.; Garcia, A.O.; Gallina, D.A.; Alvim, I.D.; Hubinger, M.D. Stability of Hibiscus Extract Encapsulated by Ionic Gelation Incorporated in Yogurt. Food Bioprocess. Technol. 2019, 12, 1500-1515. [CrossRef]

127. Pöhnl, H. Applications of Different Curing Approaches and Natural Colorants in Meat Products. In Handbook on Natural Pigments in Food and Beverages; Carle, R., Schweiggert, R.M., Eds.; Woodhead Publishing: Cambridge, UK, 2016; pp. 209-225, ISBN 978-0-08-100371-8.

128. Baldin, J.C.; Michelin, E.C.; Polizer, Y.J.; Rodrigues, I.; de Godoy, S.H.S.; Fregonesi, R.P.; Pires, M.A.; Carvalho, L.T.; FávaroTrindade, C.S.; de Lima, C.G.; et al. Microencapsulated jabuticaba (Myrciaria cauliflora) extract added to fresh sausage as natural dye with antioxidant and antimicrobial activity. Meat Sci. 2016, 118, 15-21. [CrossRef] [PubMed]

129. Sellimi, S.; Ksouda, G.; Benslima, A.; Nasri, R.; Rinaudo, M.; Nasri, M.; Hajji, M. Enhancing colour and oxidative stabilities of reduced-nitrite turkey meat sausages during refrigerated storage using fucoxanthin purified from the Tunisian seaweed Cystoseira barbata. Food Chem. Toxicol. 2017, 107, 620-629. [CrossRef] [PubMed]

130. Hamdi, M.; Nasri, R.; Dridi, N.; Moussa, H.; Ashour, L.; Nasri, M. Improvement of the quality and the shelf life of reduced-nitrites turkey meat sausages incorporated with carotenoproteins from blue crabs shells. Food Control 2018, 91, 148-159. [CrossRef]

131. Estévez, M. What's New in Meat Oxidation? In New Aspects of Meat Quality; Purslow, P.P., Ed.; Woodhead Publishing: Cambridge, UK, 2017; pp. 91-109, ISBN 978-0-08-100593-4.

132. Cunha, L.C.M.; Monteiro, M.L.G.; Costa-Lima, B.R.C.; Guedes-Oliveira, J.M.; Alves, V.H.M.; Almeida, A.L.; Tonon, R.V.; Rosenthal, A.; Conte-Junior, C.A. Effect of microencapsulated extract of pitaya (Hylocereus costaricensis) peel on color, texture and oxidative stability of refrigerated ground pork patties submitted to high pressure processing. Innov. Food Sci. Emerg. Technol. 2018, 49, 136-145. [CrossRef]

133. Porto Dalla Costa, A.; Cruz Silveira Thys, R.; De Oliveira Rios, A.; Hickmann Flôres, S. Carrot Flour from Minimally Processed Residue as Substitute of $\beta$-Carotene Commercial in Dry Pasta Prepared with Common Wheat (Triticum aestivum). J. Food Qual. 2016, 39, 590-598. [CrossRef]

134. Armellini, R.; Peinado, I.; Pittia, P.; Scampicchio, M.; Heredia, A.; Andres, A. Effect of saffron (Crocus sativus L.) enrichment on antioxidant and sensorial properties of wheat flour pasta. Fssood Chem. 2018, 254, 55-63. [CrossRef] [PubMed]

135. Sayuti, K.; Azima, F.; Marisa, M. The adition of "senduduk" fruit (Melastoma malabathricum L.) extract as colorants and antioxidant on Jackfruit straw (Artocarpus heterophyllus L.) jam. Int. J. Adv. Sci. Eng. Inf. Technol. 2015, 5, 396-402. [CrossRef]

136. Cerezal Mezquita, P.; Morales, J.; Palma, J.; Ruiz, M.D.C.; Jáuregui, M. Stability of Lutein Obtained from Muriellopsis sp biomass and used as a natural colorant and antioxidant in a mayonnaise-like dressing sauce. CyTA J. Food 2019, 17, 517-526. [CrossRef] 